\title{
On eight species of the spider genus Synagelides Strand, 1906 from China (Araneae: Salticidae)
}

\author{
Cheng WANG ${ }^{1}$, Xiao-Qi MI ${ }^{2}$, Muhammad IRFAN ${ }^{3, *} \&$ Xian-Jin PENG ${ }^{4, *}$ \\ ${ }^{1,4}$ College of Life Sciences, Hunan Normal University, Changsha, Hunan 410081, China. \\ ${ }^{1,2}$ Guizhou Provincial Key Laboratory for Biodiversity Conservation and Utilization in the Fanjing \\ Mountain Region, Tongren University, Tongren, Guizhou 554300, China. \\ ${ }^{3}$ Key Laboratory of Eco-environments in Three Gorges Reservoir Region (Ministry of Education), \\ School of Life Sciences, Southwest University, Chongqing 400715, China. \\ "Corresponding authors: xjpeng@126.com,irfanuos94@yahoo.com \\ ${ }^{1}$ Email: wchengspider@163.com \\ 2Email: mixiaoqi1018@163.com \\ ${ }^{1}$ urn:1sid:zoobank.org:author:1F79A97E-8C35-48B1-BBEB-EA1A52D80EEB
${ }^{2}$ urn:1sid:zoobank.org:author:71EEF311-23B0-42FE-AF3F-B91AE10D74BA
${ }^{3}$ urn:1sid:zoobank.org:author:4EE226DB-D810-4907-A4B6-B04F4E4241AB
${ }^{4}$ urn:1sid:zoobank.org:author:5CF67046-FAB4-43F1-AA72-ED2EB9741CD9
}

Abstract. Six new species of Synagelides Strand, 1906 are diagnosed and described: S. bohdanowiczi

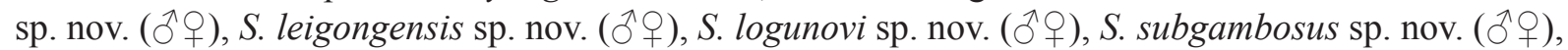
$S$. wuliangensis sp. nov. (ठㅇ) and $S$. xingdouensis sp. nov. (ठ우). The female of $S$. forkiforma Yang, Zhu \& Song, 2007 and the male of S. longus Song \& Chai, 1992 are described for the first time. Photos of the habitus and copulatory organs, as well as a distributional map, are provided.

Keywords. Agoriini, morphology, South China, taxonomy.

Wang C., Mi X.-Q., Irfan M. \& Peng X.-J. 2020. On eight species of the spider genus Synagelides Strand, 1906 from China (Araneae: Salticidae). European Journal of Taxonomy 724: 1-33.

https://doi.org/10.5852/ejt.2020.724.1153

\section{Introduction}

The genus Synagelides Strand, 1906 comprises a group of ant-like spiders distributed from the Russian Far East to Southeast Asia (Maddison 2015; WSC 2020). A total of 51 nominal species with diagnostic illustrations have been assigned to the genus, of which 27 were described only from a single sex (13 only from males and 14 only from females) (WSC 2020). Almost all species were originally described as a member of this genus except Synagelides cavaleriei (Schenkel, 1963), which was transferred from Tagoria Schenkel, 1963, a synonym of Synagelides. Most species of Synagelides have very limited distributional ranges (46 species are endemics and known only from a single country and three species are known from two countries). Bohdanowicz $(1978,1979,1987)$ has done extensive work on this 
genus, describing all species from Bhutan, Japan and Nepal, and also re-describing the type species. Seven new species and six synonyms were added by Logunov \& Hereward (2006). To date, this genus exhibits the highest species diversity in China, with 24 species, including 19 endemic ones (Song 1990; Xie \& Yin 1990; Song \& Chai 1992; Peng et al. 1998, 2002, 2003, 2008; Song \& Zhu 1998; Zhu et al. 2005; Yang et al. 2007; Liu et al. 2017; Lin \& Li 2020; Peng 2020), followed by Nepal, with 10 species, including nine endemic ones (Bohdanowicz 1979, 1987; Logunov \& Hereward 2006).

While examining Synagelides specimens from South China (Yunnan, Guizhou, Hubei and Guangxi), more than twenty species, including six new to science with both sexes, the previously unknown female of S. forkiforma Yang, Zhu \& Song, 2007 and the previously unknown male of S. longus Song \& Chai, 1992, have been identified and are described here. A re-examination of the types of S. gambosus Xie \& Yin, 1990 reveals that the retrolateral tibial apophysis of the male palp has been ignored and never illustrated or described until now. The goals of this paper are to describe and illustrate the new species as well as the previously unknown sexes of $S$. longus and $S$. forkiforma, and to present the retrolateral tibial apophysis of S. gambosus.

\section{Material and methods}

Specimens were collected mainly by beating shrubs and screening leaf-litter. All specimens were preserved in $75 \%$ ethanol and are deposited in the museum of Tongren University (TRU), Tongren, China except the types of Synagelides xingdouensis sp. nov. and the new material of S. forkiforma Yang, Zhu \& Song, 2007, which are deposited at the College of Life Sciences, Hunan Normal University (HNU), Changsha, Hunan, China.

The specimens were examined with an Olympus SZ51 stereo microscope. After dissecting from the body, epigynes were cleared in trypsin enzyme solution before examination and imaging. Left male palps, legs I and chelicerae were used for illustration. Photos were taken with a Kuy Nice CCD mounted on an Olympus BX51 compound microscope except the photos of Fig. 17, which were taken with a Canon G12 camera mounted on an Olympus BX53 compound microscope. Compound focus images were generated using Helicon Focus 6.7.1 and 3.1 software.

All measurements are given in millimeters. Leg measurements are giving as: total length (femur, patella + tibia, metatarsus, tarsus). References to figures in the literature are listed in lowercase type (fig. or figs); figures in this paper are noted with an initial capital (Fig. or Figs). Terminology follows Lin \& $\mathrm{Li}$ (2020). Abbreviations used in the text and figures are as follows:

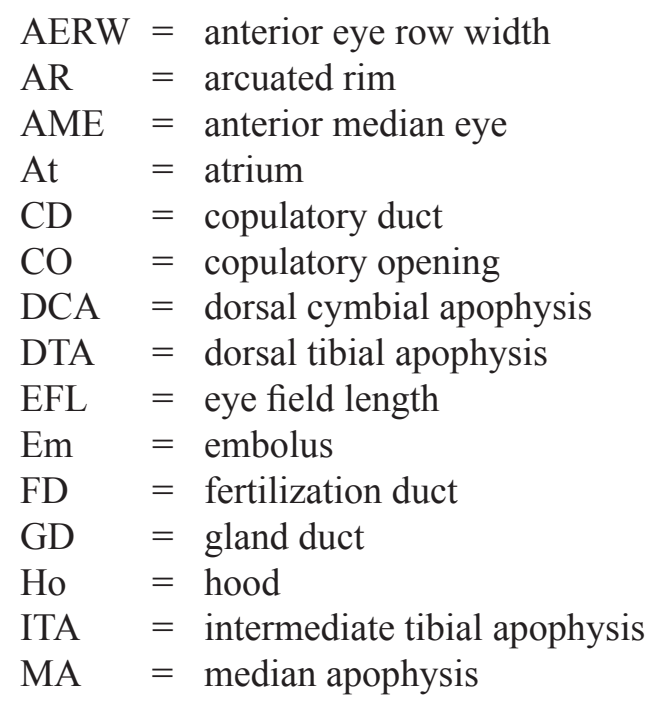




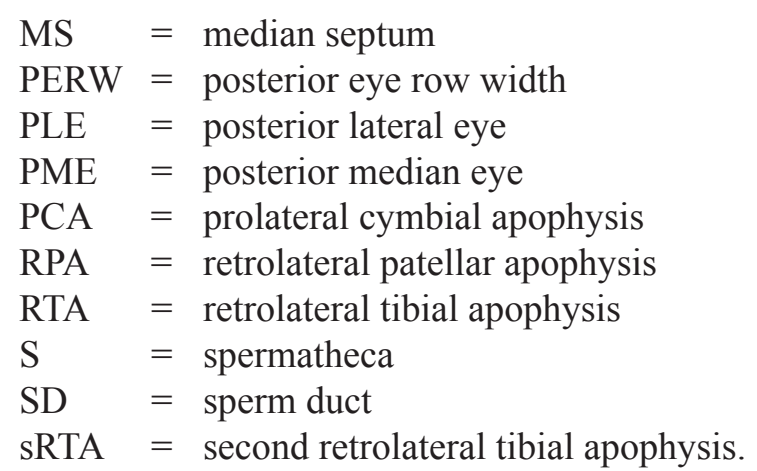

\section{Results}

Class Arachnida Cuvier, 1812

Order Araneae Clerck, 1757

Family Salticidae Blackwall, 1841

Genus Synagelides Strand, 1906

Synagelides Strand in Bösenberg \& Strand, 1906: 330 (type species: Synagelides agoriformis Strand, 1906).

Tagoria Schenkel, 1963: 393 (type species: Tagoria cavaleriei Schenkel, 1963; synonymized by Bohdanowicz 1979).

\section{Differential diagnosis}

See Kanesharatnam \& Benjamin (2020).

\section{Description}

See Kanesharatnam \& Benjamin (2020).

Synagelides bohdanowiczi sp. nov.

urn:lsid:zoobank.org:act:A1C87D1D-197A-4966-9EEA-C00D49E777CD

Figs $1-2,17 \mathrm{C}$

\section{Differential diagnosis}

Synagelides bohdanowiczi sp. nov. resembles S. gambosus (Xie \& Yin 1990: figs 1-7; Fig. 11D) and S. subgambosus sp. nov. in the S-shaped retrolateral tibial apophysis and the long and narrow median septum in the epigyne, but differs from these two species by: 1) retrolateral tibial apophysis originates from the terminal of the tibia, with the tip directed upwards in retrolateral view in $S$. bohdanowiczi sp. nov. (Fig. 1B), whereas originates from the middle of the tibia, with the tip directed horizontally towards the genital bulb in S. gambosus (Fig. 11D) and S. subgambosus sp. nov. (Fig. 11B); 2) median apophysis is horn-shaped, pointed and far away from the embolus apically in $S$. bohdanowiczi sp. nov. (Fig. 1B), whereas more broadened and very close to or partially covering the embolus in S. gambosus (Fig. 11D) and S. subgambosus sp. nov. (Fig. 11B); 3) atrium is elongated oval, longer than wide, lacking wrinkles in S. bohdanowiczi sp. nov. (Fig. 2A), whereas wider than long, with distinct wrinkles in S. subgambosus sp. nov. (Fig. 12A); 4) spermathecae extend obliquely in dorsal view in S. bohdanowiczi sp. nov. (Fig. 2C), whereas extend transversely in S. gambosus (Xie \& Yin 1990: fig. 7) and S. subgambosus sp. nov. (Fig. 12C). 


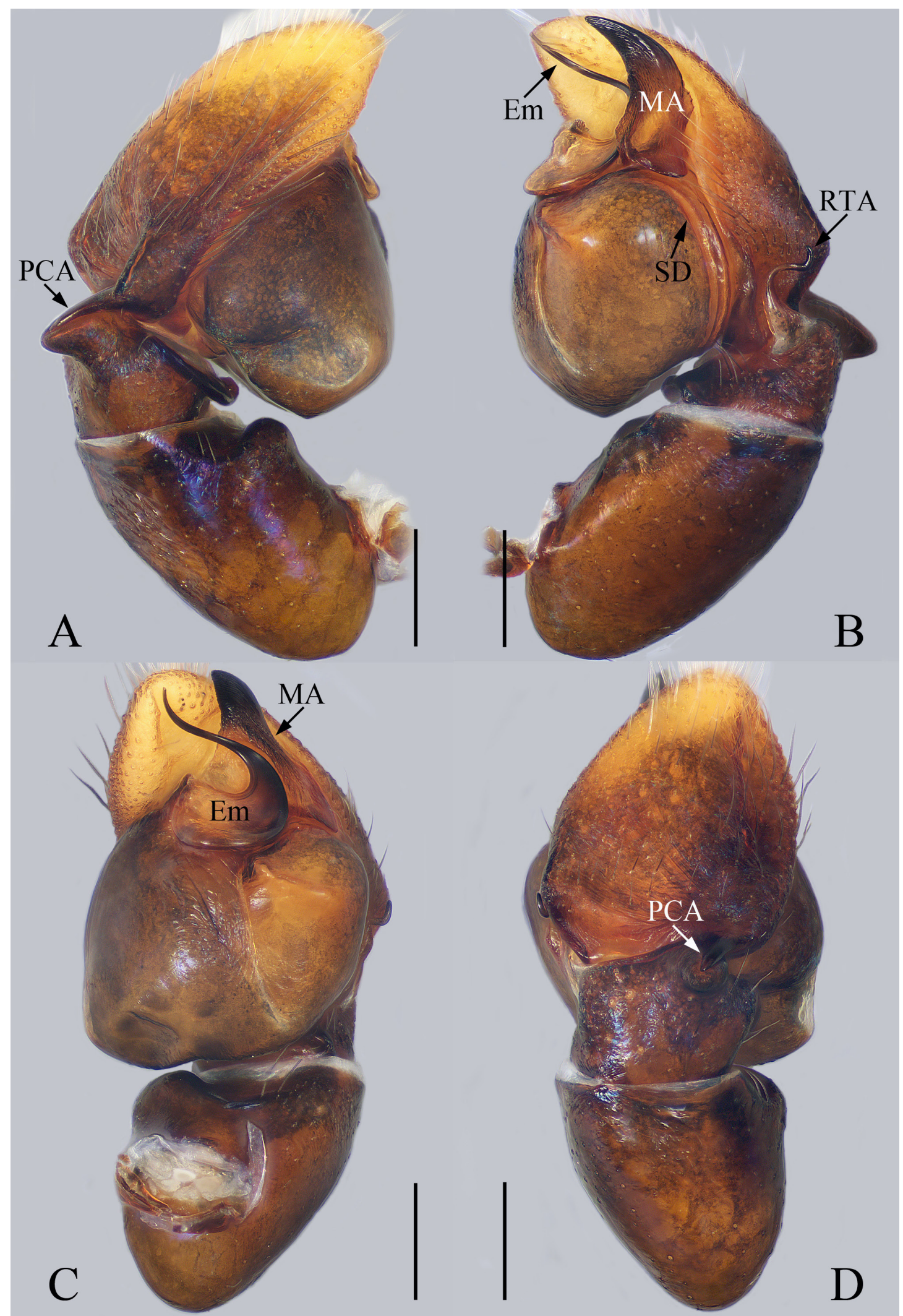

Fig. 1. Male palp of Synagelides bohdanowiczi sp. nov., holotype, $\widehat{\partial}$ (TRU-Salticid-0010). A. Prolateral view. B. Retrolateral view. C. Ventral view. D. Dorsal view. Abbreviations: see Material and methods. Scale bars $=0.1 \mathrm{~mm}$. 

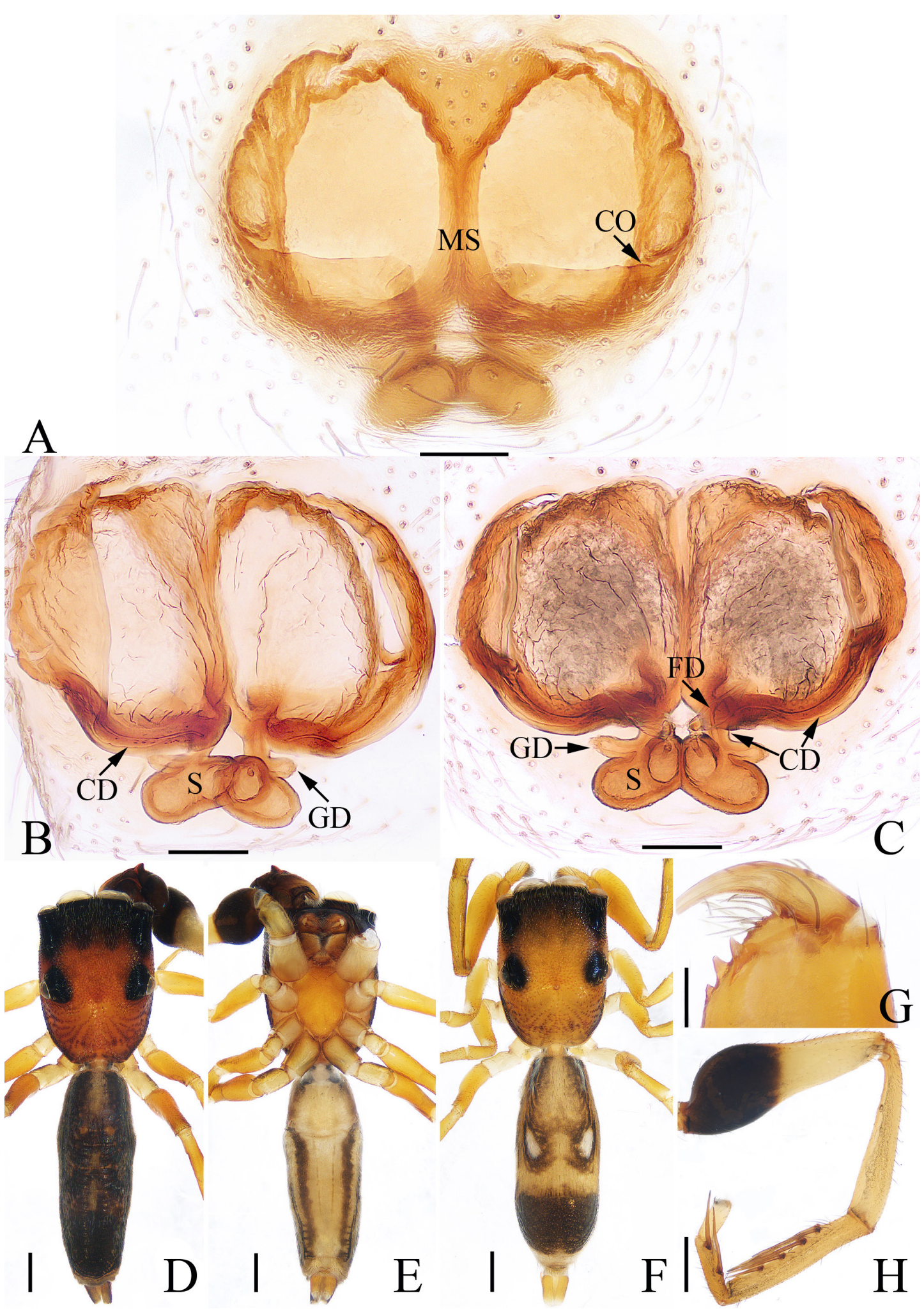

Fig. 2. Synagelides bohdanowiczi sp. nov. A-C, F. Paratype, $q$ (TRU-Salticid-0011). D-E, G-H. Holotype, $\widehat{\jmath}$ (TRU-Salticid-0010). A. Epigyne, ventral view. B. Epigyne, dorsolateral view. C. Epigyne, dorsal view. D. Habitus, dorsal view. E. Habitus, ventral view. F. Habitus, dorsal view. G. Chelicerae, dorsal view. H. Leg I, prolateral view. Abbreviations: see Material and methods. Scale bars: $\mathrm{A}-\mathrm{C}, \mathrm{G}=0.1 \mathrm{~mm}$; D-F, $\mathrm{H}=0.5 \mathrm{~mm}$. 


\section{Etymology}

The specific name is a patronym in honor of Dr Andrzej Bohdanowicz, who contributed extensively to the taxonomy of the genus Synagelides.

\section{Material examined}

\section{Holotype}

CHINA - गे; Guangxi Province, Shangsi County, Shiwandashan National Forest Park; $21^{\circ} 52.97^{\prime}$ N, 10754.88' E; ca 700 m a.s.1.; 6 Oct. 2018; Xiaoqi Mi, Cheng Wang, Guijie Tian and Hong Liu leg.; TRU-Salticid-0010.

\section{Paratype}

CHINA • 1 q; same collection data as for holotype; TRU-Salticid-0011.

\section{Description}

\section{Male (holotype)}

Total length 5.04. Carapace 2.04 long, 1.52 wide. Abdomen 2.83 wide, 1.02 wide. Eye sizes and interdistances: AME 0.48, ALE 0.26, PLE 0.24, AREW 1.48, PERW 1.50, EFL 1.15. Legs: I 6.11 (1.88, $3.18,0.61,0.44)$, II $3.87(1.12,1.46,0.85,0.44)$, III 4.05 (1.15, 1.44, 1.02, 0.44), IV $5.47(1.44,2.10$, $1.39,0.54)$. Carapace (Fig. 2D) stippled, red-brown, anterior surface and eye base dark, covered by brown hairs anteriorly and sparse white hairs posteriorly. Fovea oval, hollowed. Chelicerae (Fig. 2G) yellow, with two promarginal teeth and one retromarginal tooth fissident. Endites (Fig. 2E) yellowbrown, slightly longer than wide, inner margins pale with dense hairs. Labium (Fig. 2E) gradually narrowed, apically bearing dense hairs. Sternum (Fig. 2E) yellow, scutiform. Legs yellow to red-yellow except the basal half of femur I dark. Spination of leg I (Fig. 2H): femur v2-2-2-2; metatarsus v0-1-1. Abdomen (Fig. 2D-E) elongated; dorsum dark-brown, the posterior one-third portion darker, with a pair of round spots antero-medially, and an inconsecutive, longitudinal pale-brown stripe extending from the anterior margin to the posterior one-third portion; venter gray, with two longitudinal dark-brown stripes bilaterally and two longitudinal lines medially. Palp (Figs 1A-D, 17C): patella about 1.5 times longer than wide in retrolateral view; retrolateral tibial apophysis S-shaped, broadened at base; cymbium hairy, with sclerotized prolateral apophysis tapering to a pointed tip in dorsal view; bulb bulged, with the sperm duct extending along the margin; embolus with flatted, semicircular base, distal portion flagelliform, and tip slightly pointed, reaching the cymbium apex; median apophysis ox horn-shaped in retrolateral view, the distal half sclerotized.

Female (allotype, TRU-Salticid-0011)

Total length 4.85. Carapace 1.93 long, 1.37 wide. Abdomen 2.70 long, 1.01 wide. Eye sizes and interdistances: AME 0.47, ALE 0.25, PLE 0.24, AREW 1.40, PERW 1.45, EFL 1.10. Legs: I 4.83 (1.46, 2.44, 0.49, 0.44), II 3.54 (1.05, 1.29, 0.76, 0.44), III 3.68 (1.07, 1.24, 0.93, 0.44), IV 5.21 (1.37, 2.01, $1.29,0.54$ ). Habitus (Fig. 2F) similar to that of male except paler and with a pair of white oval patches on the dorsum of the abdomen. Epigyne (Fig. 2A-C) wider than long; atrium large, separated by a ) (-shaped median septum; copulatory openings located bilaterally; copulatory ducts long, descending obliquely before extending transversely, and then descending posteriorly along the longitudinal axis, terminally with short gland ducts; spermathecae long, oval, touching each other anteriorly; fertilization ducts anterior to spermathecae.

\section{Distribution}

China (Guangxi) (Fig. 18). 


\section{Comments}

At first glance, the male and female look different in the markings of the abdomen. However, the male has blurry markings almost identical to the female. Furthermore, both of them were collected from the same locality and the sexual dimorphism in the morphology of the copulatory organs is consistent with sexual dimorphism in related species (S. gambosus and S. subgambosus sp. nov.). Based on this evidence, they are proposed to be the same species.

Synagelides forkiforma Yang, Zhu \& Song, 2007

Figs 3-4, 17B

Synagelides forkiforma Yang, Zhu \& Song, 2007: 2, figs 2a-d $(\mathrm{d}=\widehat{\jmath})$.

\section{Differential diagnosis}

The male of Synagelides forkiforma can easily be distinguished from all other congeners by the presence of a short spine-shaped prong on the ventral surface of the retrolateral tibial apophysis. The female of S. forkiforma resembles that of S. lushanensis Xie \& Yin, 1990 (Xie \& Yin 1990: figs 8-15) in having an anterior epigynal hood and a pair of lateral arcuated rims, but differs in: 1) epigynal hood is about one-third as long as epigynum in S. forkiforma (Fig. 4A), whereas about one-fifth as long as epigynum in S. lushanensis (Xie \& Yin 1990: fig. 14); 2) median septum is almost triangular in S. forkiforma (Fig. 4A), whereas trapeziform in S. lushanensis (Xie \& Yin 1990: fig. 14).

\section{Material examined}

CHINA -1 o, 2 우; Yunnan Province, Fugong County, Maji Township, Flum above Gaxai R. near, Majimi Village, Gaoligongshan National Nature Reserve; $27^{\circ} 24.18^{\prime}$ N, $98^{\circ} 49.47^{\prime}$ E; ca 1500 m a.s.1.; 28 Apr. 2004; C. Griswold and D.H. Kavanaugh leg.; HNU-20040428-01-03.

\section{Description}

Male (HNU-20040428-01)

Total length 4.04. Carapace 1.81 long, 1.37 wide. Abdomen 2.15 long, 1.04 wide. Eye sizes and interdistances: AME 0.42, ALE 0.24, PLE 0.22, AREW 1.33, PERW 1.41, EFL 1.02. Legs: I 7.25 (2.39, $3.90,0.57,0.39)$, II 3.53 (1.12, 1.34, 0.68, 0.39), III 3.70 (1.12, 1.34, 0.85, 0.39), IV lost. Carapace (Fig. 4D) stippled, yellow, with a pair of dark patches anteriorly, covered by sparse hairs. Eye base black except the AME base brown. Fovea oval, hollowed. Chelicerae (Fig. 4G) yellow, with two promarginal teeth and one retromarginal tooth fissident. Endites (Fig. 4E) pale yellow, slightly longer than wide, the inner margin with hairs. Labium (Fig. 4E) colored as labium, with dense hairs apically. Sternum (Fig. 4E) pale yellow, scutiform. Legs pale yellow to yellow. Spination of leg I (Fig. 4H): femur v22-2-2-1; metatarsus v0-2-2. Abdomen (Fig. 4D-E) elongated; dorsum brown, with a pale transverse band and two pairs of muscle depressions medially, herringbone stripes indistinct; venter gray-white, with irregular brown patches median-posteriorly. Palp (Figs 3A-D, 17B): patella slightly longer than wide in retrolateral view; retrolateral tibial apophysis slender and more than half as long as cymbium, with a ventral, short spine-shaped prong; the second retrolateral tibial apophysis paliform; cymbium hairy, with dorsal and prolateral apophyses; bulb inflated, with sperm duct sinuous in retrolateral view; embolus spiraling and tapering to a slightly pointed tip that reaches cymbium apex; median apophysis complicated, with processes.

Female (HNU-20040428-02)

Total length 4.41. Carapace 1.98 long, 1.47 wide. Abdomen 2.34 long, 1.25 wide. Eye sizes and interdistances: AME 0.41, ALE 0.23, PLE 0.22, AREW 1.33, PERW 1.54, EFL 1.11. Legs: I 5.39 (1.66, $2.71,0.63,0.39)$, II $3.44(1.05,1.32,0.68,0.39)$, III $3.59(1.05,1.30,0.85,0.39)$ IV 5.02(1.37, 2.02, 


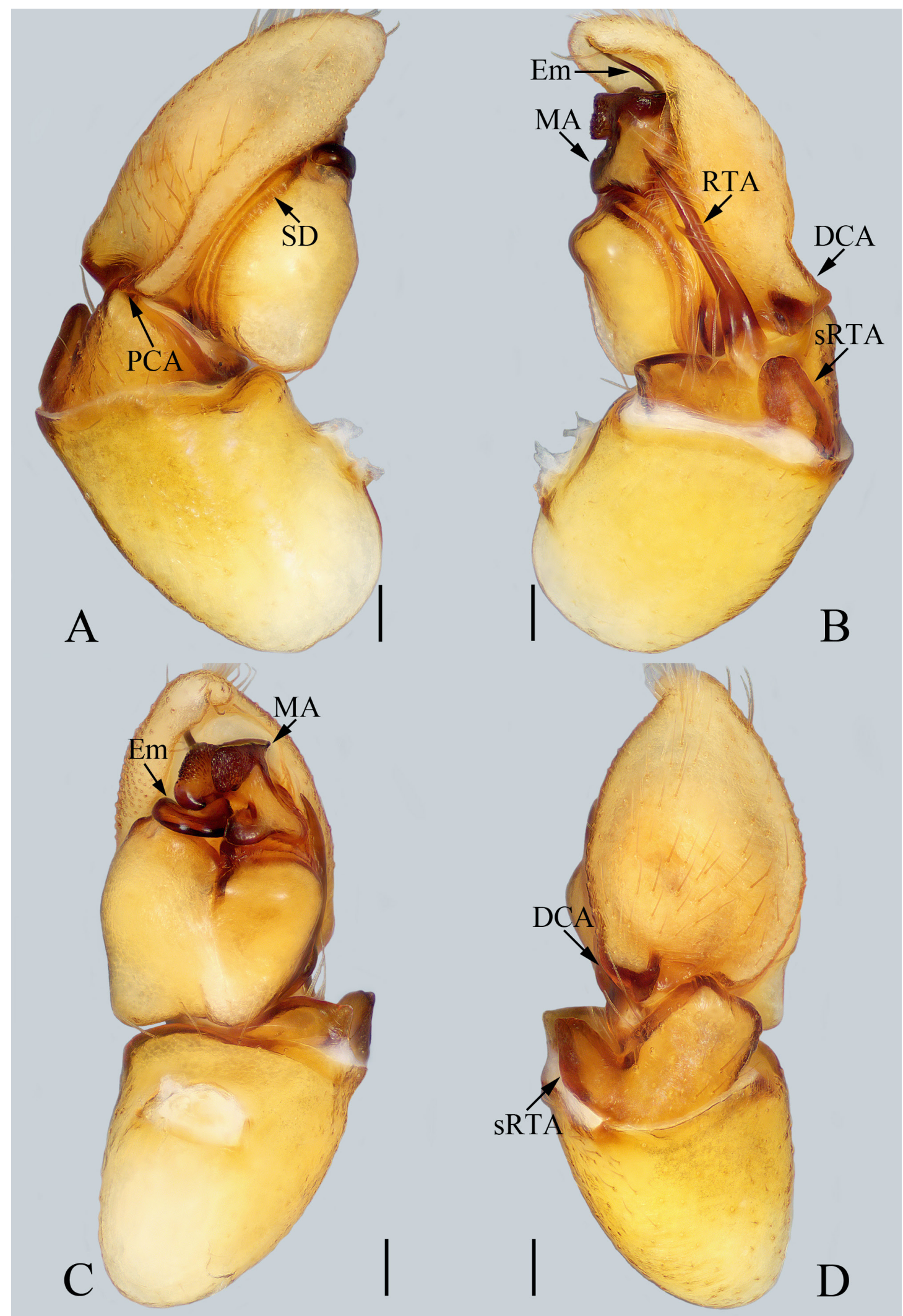

Fig. 3. Male palp of Synagelides forkiforma Yang, Zhu \& Song, 2007 (HNU-20040428-01). A. Prolateral view. B. Retrolateral view. C. Ventral view. D. Dorsal view. Abbreviations: see Material and methods. Scale bars $=0.1 \mathrm{~mm}$. 

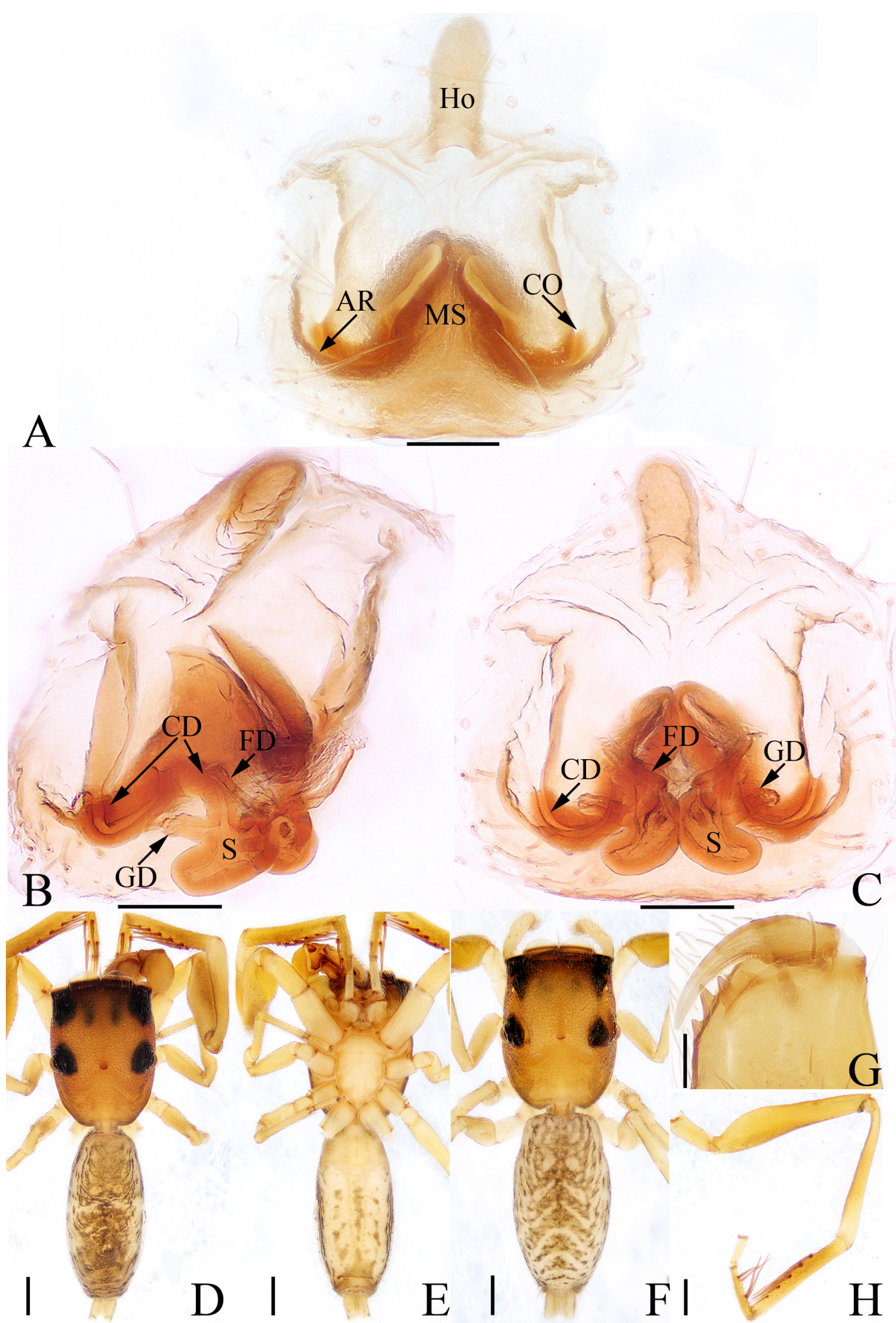

Fig. 4. Synagelides forkiforma Yang, Zhu \& Song, 2007. A-C, F. क (HNU-20040428-02). D-E, G-H. § (HNU-20040428-01). A. Epigyne, ventral view. B. Epigyne, dorsolateral view. C. Epigyne, dorsal view. D. Habitus, dorsal view. E. Habitus, ventral view. F. Habitus, dorsal view. G. Chelicerae, dorsal view. H. Leg I, prolateral view. Abbreviations: see Material and methods. Scale bars: A-C, G = $0.1 \mathrm{~mm}$; D-F, $\mathrm{H}=0.5 \mathrm{~mm}$. 
1.22, 0.41). Habitus (Fig. 4F) similar to that of male except paler and lacking the pale transverse band on the dorsum of abdomen. Epigyne (Fig. 4A-C) longer than wide, with an anterior hood about 2.5 times longer than wide and a pair of lateral arcuated rims; atrium large, separated by a triangular median septum; copulatory openings located postero-laterally; copulatory ducts almost S-shaped, terminating with gland ducts, which almost extend transversely; spermathecae reniform, touching each other anteriorly; fertilization ducts slightly longer than gland ducts, extending antero-obliquely.

\section{Distribution}

China (Yunnan) (Fig. 18).

\section{Comments}

The known drawings of the holotype of S. forkiforma are difficult to interpret due to poor print quality. Although the type specimens were not examined in the present contribution, the clear, original drawings of the holotype provided by Prof. Zi-Zhong Yang, who described the species, were compared with the specimens examined here from Fugong County. The male from Fugong is almost indistinguishable from the holotype, and the female from Fugong shares similar markings with the Fugong male. Fugong County is also near the type locality (the distance between the collecting site in Fugong and type locality is less than 150 kilometers) and both localities belong to Gaoligong Mountain and have similar climatic and environmental conditions. Based on the above evidence, the specimens collected from Fugong County are identified here as new material of $S$. forkiforma.

Synagelides leigongensis sp. nov.

urn:1sid:zoobank.org:act:67AE40F6-A67E-4CB2-ADA8-E107C10C8531

Figs 5-6

\section{Differential diagnosis}

Synagelides leigongensis sp. nov. can easily be distinguished from all other congeners by: 1) retrolateral tibial apophysis is bifurcated basally (not bifurcated, or bifurcated medially or apically in that of other congeners); 2) epigyne lacks median septum and has a large anterior arcuated rim covering almost half the epigynal length.

\section{Etymology}

The species name is derived from the type locality; adjective.

\section{Material examined}

\section{Holotype}

CHINA - \; Guizhou Province, Leishan County, Danjiang Township, Leigongshan National Nature Reserve; $26^{\circ} 22.15^{\prime} \mathrm{N}, 108^{\circ} 10.69^{\prime} \mathrm{E}$; ca $1290 \mathrm{~m}$ a.s.l.; 19 Jul. 2017; Cheng Wang et al. leg.; TRUSalticid-0012.

\section{Paratypes}

CHINA・1 $\widehat{\partial}, 2$ 우; same collection data as for holotype; TRU-Salticid-0013 to 0015.

\section{Description}

Male (holotype)

Measurements. Total length 3.69. Carapace 1.70 long, 1.19 wide. Abdomen 2.03 long, 1.14 wide. Eye sizes and inter-distances: AME 0.37, ALE 0.19, PLE 0.18, AREW 1.19, PERW 1.22, EFL 0.95. Legs: I $4.76(1.46,2.39,0.54,0.37)$, II $3.05(0.95,1.10,0.63,0.37)$, III $3.20(0.95,1.05,0.83,0.37)$, IV 


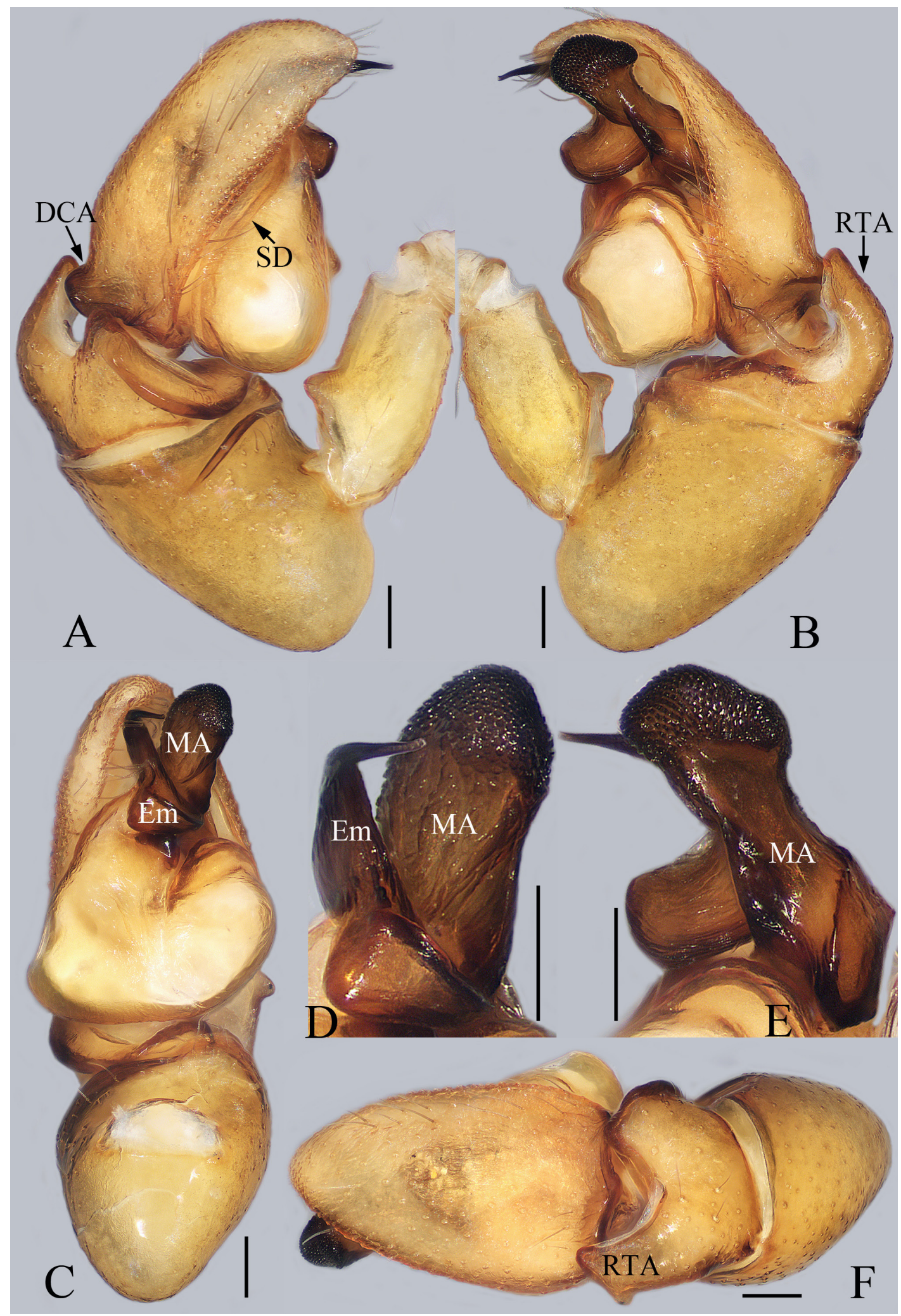

Fig. 5. Male palp of Synagelides leigongensis sp. nov. A-C, F. Holotype, $\widehat{\jmath}$ (TRU-Salticid-0012). D-E. Paratype, (TRU-Salticid-0013). A. Prolateral view. B. Retrolateral view. C. Ventral view. D. Embolus and median apophysis, ventral view. E. Embolus and median apophysis, retrolateral view. F. Dorsal view. Abbreviations: see Material and methods. Scale bars $=0.1 \mathrm{~mm}$. 


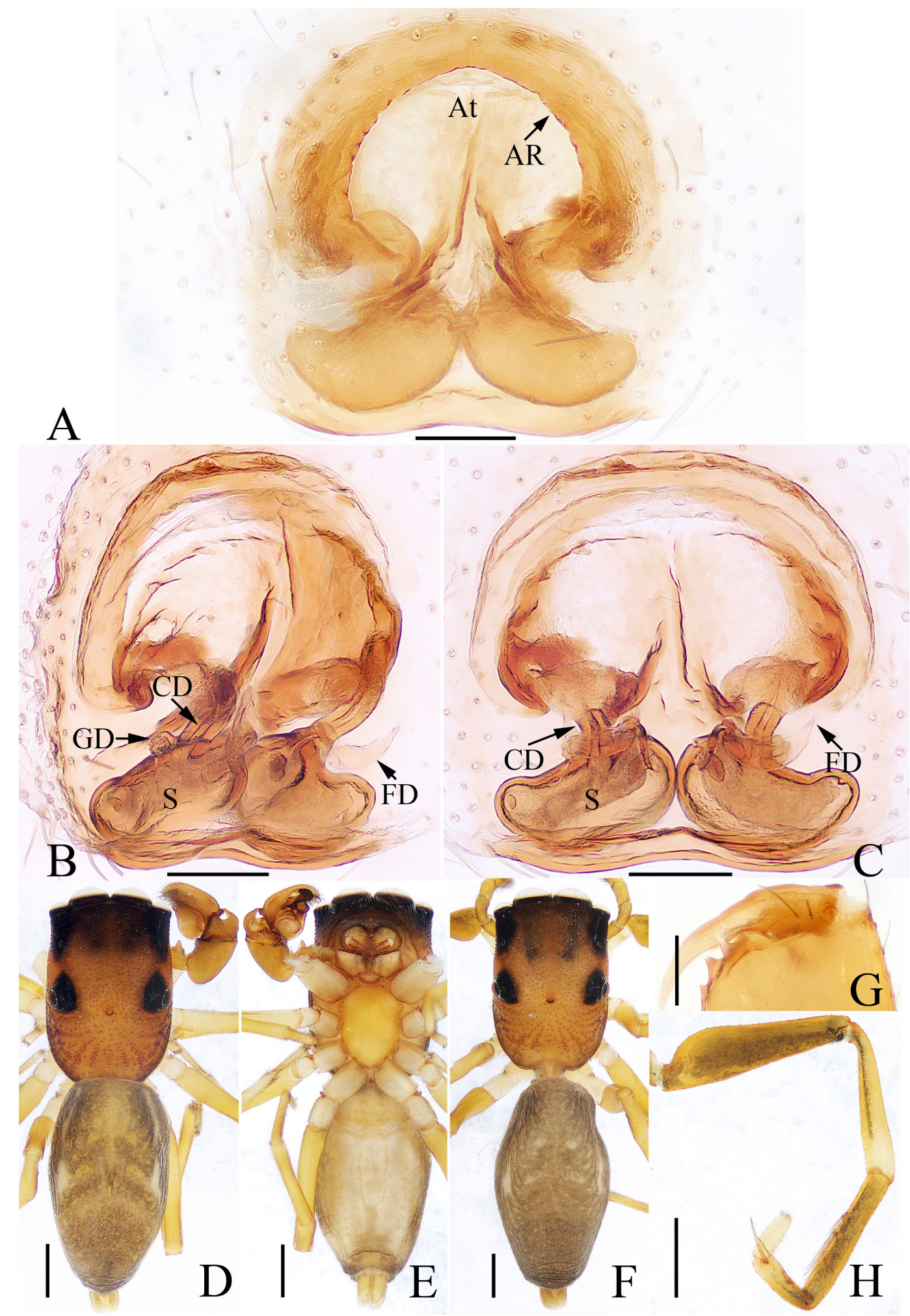

Fig. 6. Synagelides leigongensis sp. nov. A-C, F. Paratype,, (TRU-Salticid-0014). D-E, G-H. Holotype, $\widehat{\widehat{O}}$ (TRU-Salticid-0012). A. Epigyne, ventral view. B. Epigyne, dorsolateral view. C. Epigyne, dorsal view. D. Habitus, dorsal view. E. Habitus, ventral view. F. Habitus, dorsal view. G. Chelicerae, dorsal view. H. Leg I, prolateral view. Abbreviations: see Material and methods. Scale bars: A-C, G $=0.1 \mathrm{~mm}$; $\mathrm{D}-\mathrm{F}, \mathrm{H}=0.5 \mathrm{~mm}$. 
$4.36(1.22,1.59,1.07,0.48)$. Carapace (Fig. 6D) stippled, yellow-brown, with a pair of irregular dark patches anteriorly. Fovea oval, hollowed. Chelicerae (Fig. 6G) yellow, with two promarginal teeth and one retromarginal tooth fissident. Endites, labium, and sternum (Fig. 6E) colored as chelicerae. Legs pale yellow to yellow except leg I interspersed with brown. Spination of leg I (Fig. 6H): femur v2-2-2; metatarsus v0-1-1. Abdomen (Fig. 6D-E) elongated; dorsum brown with lateral white patches anteromedially and two pairs of muscle depressions; venter grey-white, terminally brown, with brown dots. Palp (Fig. 5A-F): patella about 1.5 times longer than wide; retrolateral tibial apophysis bifurcated, the ventral ramus transparent and pointed apically, the dorsal ramus bent medially and blunt apically; cymbium with a discal dorsal apophysis; embolus flattened, strongly curved terminally and slightly pointed apically; median apophysis well-developed, sclerotized, terminally with little tubercles.

Female (allotype, TRU-Salticid-0014)

Total length 4.48. Carapace 1.59 long, 1.34 wide. Abdomen 2.41 long, 1.34 wide. Eye sizes and interdistances: AME 0.41, ALE 0.23, PLE 0.22, AREW 1.31, PERW 1.35, EFL 1.04. Legs: I 4.28 (1.30, 2.10, $0.51,0.37)$, II $3.15(0.98,1.15,0.63,0.39)$, III 3.37 ( $0.98,1.15,0.83,0.41)$, IV $4.57(1.24,1.73,1.12,0.48)$. Habitus (Fig. 6F) similar to that of male except paler. Epigyne (Fig. 6A-C) slightly longer than wide, with a large anterior arcuated rim; atrium large, almost occupying half the epigyne; copulatory openings located bilaterally; copulatory ducts short, terminally with short gland ducts; spermathecae inflated, boat-shaped; fertilization ducts extending transversely and slightly curved medially in dorsal view.

\title{
Distribution
}

China (Guizhou) (Fig. 18).

\section{Comments}

The pairing of this species and the following ones are mainly based on the fact that both sexes were collected from the same sites and share similar markings. Moreover, the sexual dimorphism between the male and female of $S$. leigongensis sp. nov. is consistent with sexual dimorphism found in related species.

\author{
Synagelides logunovi sp. nov. \\ urn:1sid:zoobank.org:act:A1084EB3-8272-41CF-A76D-48167690FD3F
}

Figs $7-8,17 \mathrm{~A}$

\section{Differential diagnosis}

The male of Synagelides logunovi sp. nov. can be easily distinguished from congeners by the presence of a retrolateral patellar apophysis, which is absent in all other congeners. The female of $S$. logunovi sp. nov. resembles that of $S$. yinae Liu, Chen, Xu \& Peng, 2017 (Liu et al. 2017: figs 7a-d, 8a-b) in the general shape of the copulatory organs, but differs in: 1) epigyne is wider than long in $S$. logunovi sp. nov. (Fig. 8A), whereas longer than wide in S. yinae (Liu et al. 2017: figs 7c, 8a); 2) the distance between the hood and the apex of median septum is almost as long as hood in $S$. logunovi sp. nov. (Fig. 8A), whereas more than two times as long as hood in S. yinae (Liu et al. 2017: figs 7c, 8a); 3) spermathecae are pyriform in $S$. logunovi sp. nov. (Fig. 8B-C), whereas elongated oval in S. yinae (Liu et al. 2017: figs 7d, 8b).

\section{Etymology}

The specific name is the patronym in honor of Dr Dmitri V. Logunov (Manchester, UK), who contributed significantly to the taxonomy of the genus Synagelides. 

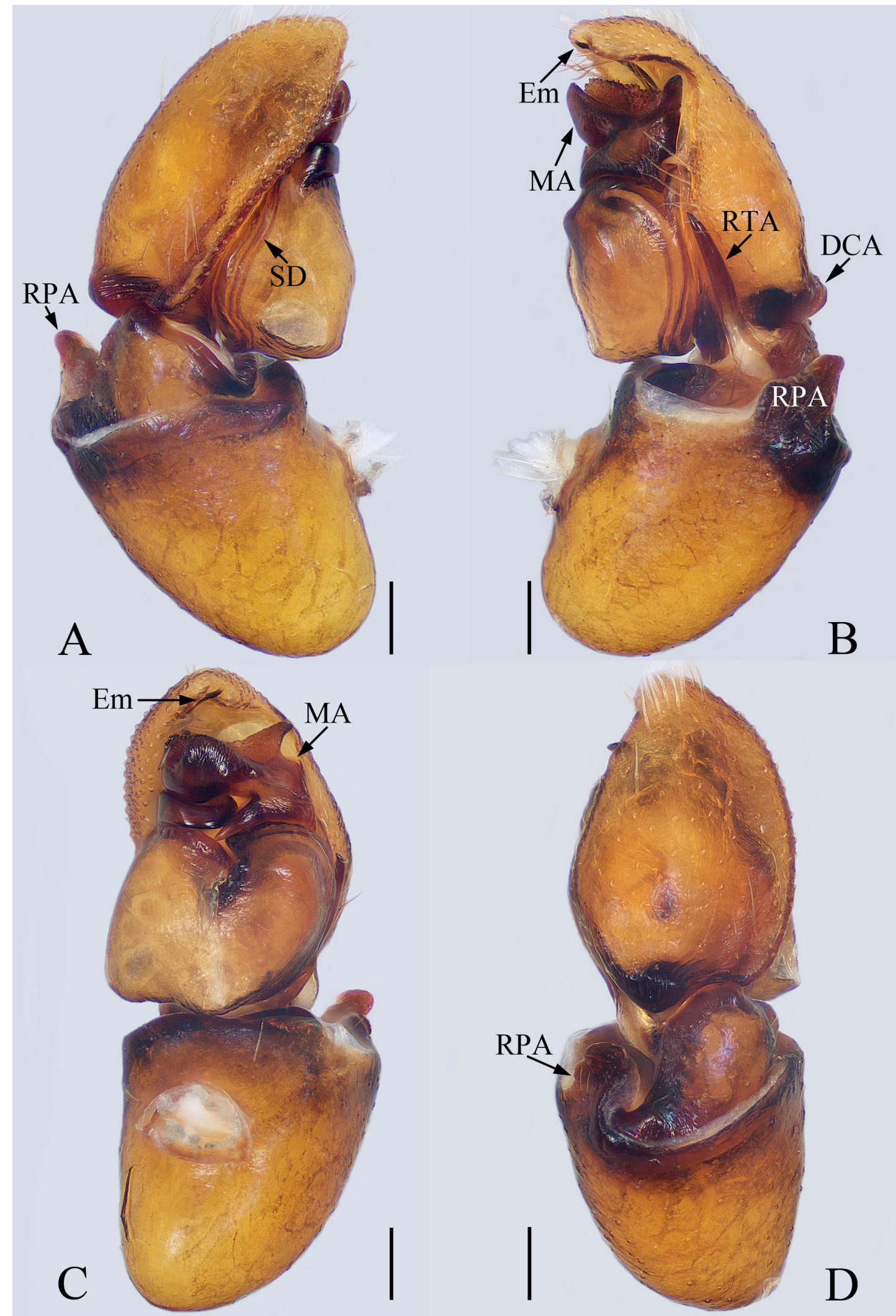

Fig. 7. Male palp of Synagelides logunovi sp. nov., holotype, $\widehat{\partial}$ (TRU-Salticid-0016). A. Prolateral view. B. Retrolateral view. C. Ventral view. D. Dorsal view. Abbreviations: see Material and methods. Scale bars $=0.1 \mathrm{~mm}$. 


\section{Ho}

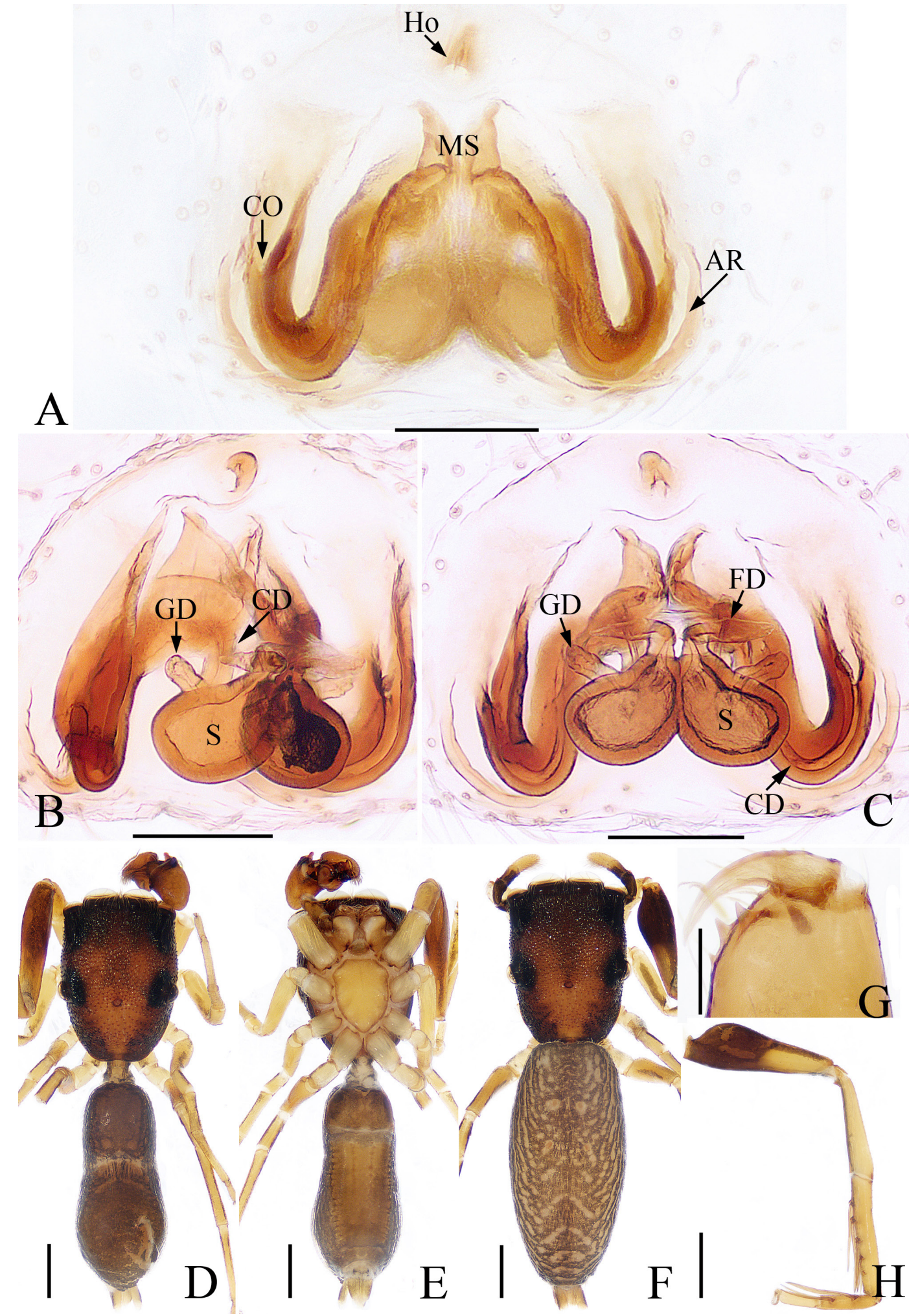

Fig. 8. Synagelides logunovi sp. nov. A-C, F. Paratype, $q$ (TRU-Salticid-0017). D-E, G-H. Holotype, $\sigma^{\lambda}$ (TRU-Salticid-0016). A. Epigyne, ventral view. B. Epigyne, dorsolateral view. C. Epigyne, dorsal view. D. Habitus, dorsal view. E. Habitus, ventral view. F. Habitus, dorsal view. G. Chelicerae, dorsal view. H. Leg I, prolateral view. Abbreviations: see Material and methods. Scale bars: A-C, G $=0.1 \mathrm{~mm}$; $\mathrm{D}-\mathrm{F}, \mathrm{H}=0.5 \mathrm{~mm}$. 


\section{Material examined}

Holotype

CHINA - O'; Yunnan Province, Nanjian County, Baohua Township, Apaxin Village, Wuliangshan National Nature Reserve; $24^{\circ} 51.60^{\prime} \mathrm{N}, 100^{\circ} 26.00^{\prime}$ E; ca $2310 \mathrm{~m}$ a.s.1.; 11 Aug. 2015; Cheng Wang, Zhaolin Liao, Peng Luo and Gaotao Liu leg.; TRU-Salticid-0016.

\section{Paratypes}

CHINA -3 우; same collection data as for holotype; TRU-Salticid-0017 to 0019.

\section{Description}

\section{Male (holotype)}

Total length 3.58. Carapace 1.44 long, 1.11 wide. Abdomen 1.94 long, 0.84 wide. Eye sizes and interdistances: AME 0.36, ALE 0.19, PLE 0.18, AREW 1.06, PERW 1.13, EFL 0.88. Legs: I $3.75(1.15,1.85$, 0.46, 0.29), II 2.40 (0.80, 0.90, 0.51, 0.29), III 2.64 (0.78, 0.90, 0.64, 0.32), IV 3.49 (0.98, 1.34, 0.85, 0.32). Carapace (Fig. 8D) stippled, yellow-brown to dark-brown, eye base black, without distinct patches. Fovea oval, hollowed. Chelicerae (Fig. 8G) pale yellow, with two promarginal teeth and one retromarginal tooth. Endites (Fig. 8E) yellow, with paler prolateral side. Labium (Fig. 8E) brown, paler apically. Sternum (Fig. 8E) yellow. Legs pale yellow to yellow except femur I and the venter of patella I brown. Spination of leg I (Fig. 8H): femur v2-2-2-2-2; metatarsus v0-2-2. Abdomen (Fig. 8D-E) elongated, contracted medially and slightly broadened posteriorly; dorsum dark-brown, with a narrow transverse pale stripe and two pairs of muscle depressions, posterior herringbone stripes indistinct; venter pale brown. Palp (Figs 7A-D, 17A): patella slightly longer than wide, distally with sclerotized and flattened retrolateral apophysis; retrolateral tibial apophysis slender, about half as long as cymbium and pointed apically; cymbium hairy, with a distal apophysis; embolus coiled spirally, the basal half almost completely covered by median apophysis in retrolateral view; median apophysis sclerotized and with processes.

Female (allotype, TRU-Salticid-0017)

Total length 3.75. Carapace 1.46 long, 1.12 wide. Abdomen 2.33 long, 1.12 wide. Eye sizes and interdistances: AME 0.36, ALE 0.20, PLE 0.19, AREW 1.11, PERW 1.16, EFL 0.84. Legs: I (1.15, other sections lost), II 2.46 (0.76, 0.90, 0.51, 0.29), III $2.61(0.76,0.90,0.66,0.29)$ IV 3.49 (0.98, 1.37 , $0.82,0.32$ ). Habitus (Fig. 8F) similar to that of male except paler, lacking abdominal contraction and the transverse pale stripe on the dorsum of the abdomen. Epigyne (Fig. 8A-C) wider than long, with an anterior hood slightly longer than wide and a pair of lateral arcuated rims; atrium separated by a big, irregular median septum; copulatory openings located bilaterally; copulatory ducts S-shaped, terminally with short gland ducts extending obliquely; spermathecae pyriform, touching each other antero-medially; fertilization ducts extending transversely.

\section{Distribution}

China (Yunnan) (Fig. 18).

\section{Synagelides longus Song \& Chai, 1992}

Figs 9-10

Synagelides longus Song \& Chai, 1992: 82, fig. 10a-c $(d=q)$.

Synagelides longus - Song \& Li 1997: 441, fig. 52a-c (+). — Song et al. 1999: 561, fig. 319h ()).

\section{Differential diagnosis}

Synagelides longus resembles S. palpalis Żabka, 1985 (Żabka 1985: figs 573-580; Fig. 17D) in the general shape of the copulatory organs and habitus, but differs in: 1) retrolateral tibial apophysis is shorter than half the cymbial length, slightly broadened medially and curved apically in retrolateral view 


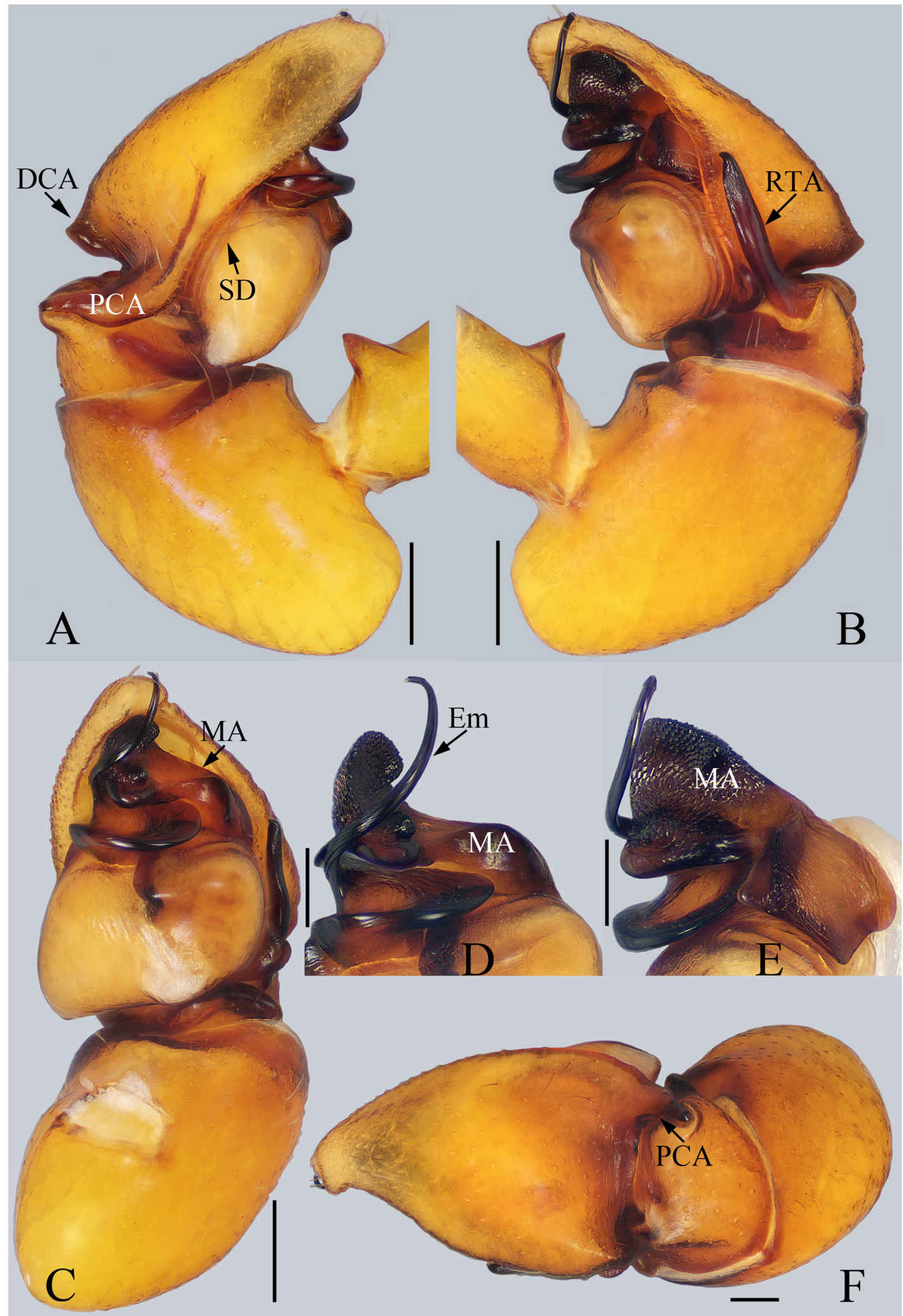

Fig. 9. Male palp of Synagelides longus Song \& Chai, 1992 (TRU-Salticid-0020). A. Prolateral view. B. Retrolateral view. C. Ventral view. D. Embolus and median apophysis, ventral view. E. Embolus and median apophysis, retrolateral view. F. Dorsal view. Abbreviations: see Material and methods. Scale bars $=0.1 \mathrm{~mm}$. 


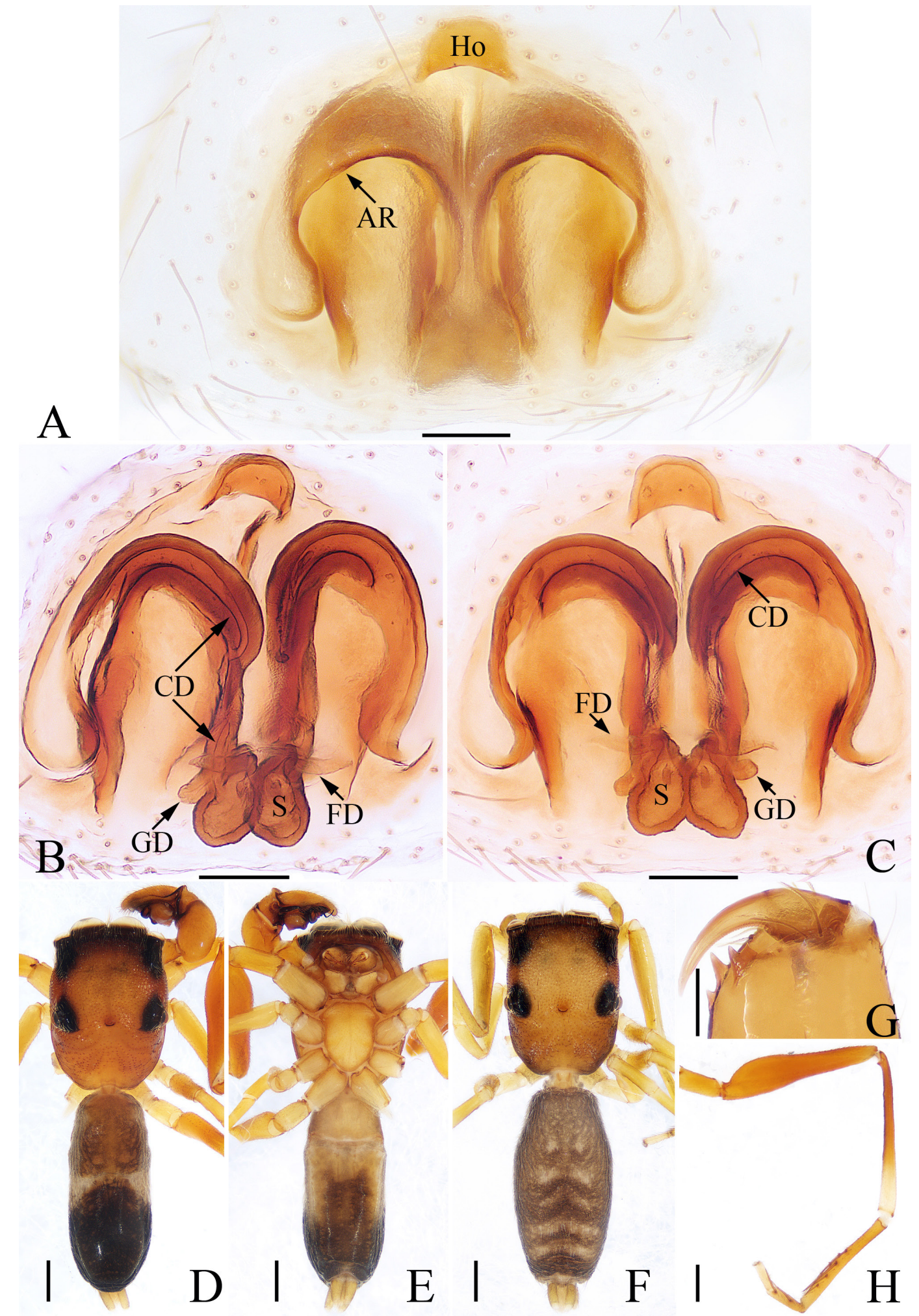

Fig. 10. Synagelides longus Song \& Chai, 1992. A-C, F. $९$ (TRU-Salticid-0024). D-E, G-H. $ڤ$ (TRUSalticid-0020). A. Epigyne, ventral view. B. Epigyne, dorsolateral view. C. Epigyne, dorsal view. D. Habitus, dorsal view. E. Habitus, ventral view. F. Habitus, dorsal view. G. Chelicerae, dorsal view. H. Leg I, prolateral view. Abbreviations: see Material and methods. Scale bars: A-C, G $=0.1 \mathrm{~mm}$; D-F, $\mathrm{H}=0.5 \mathrm{~mm}$. 
in S. longus (Fig. 9B), whereas longer than half the cymbial length, tapered and straight in S. palpalis (Fig. 17D); 2) epigynal hood is about two times wider than long in S. longus (Fig. 10A), whereas about two times longer than wide in S. palpalis (Żabka 1985: fig. 577).

\section{Material examined}

CHINA • 4 $\widehat{\partial}, 4$ + $q$; Guizhou Province, Jiangkou County, Taiping Township, Kuaichang Village; $27^{\circ} 53.10^{\prime} \mathrm{N}, 108^{\circ} 48.85^{\prime} \mathrm{E}$; ca $540 \mathrm{~m}$ a.s.1.; 8-10 May 2013, Xiaoqi Mi et al. leg.; TRU-Salticid-0020 to 0027 .

\section{Description}

Male (TRU-Salticid-0020)

Total length 4.44. Carapace 1.93 long, 1.48 wide. Abdomen 2.48 long, 1.04 wide. Eye sizes and interdistances: AME 0.44, ALE 0.24, PLE 0.22, AREW 1.37, PERW 1.44, EFL 1.11. Legs: I 7.08 (2.20, 3.95, 0.56, 0.37), II 3.75 (1.15, 1.41, 0.80, 0.39), III 3.93 (1.12, 1.41, 1.01, 0.39), IV 6.06 (1.49, 2.84, 1.32, 0.41). Carapace (Fig. 10D) stippled, red-brown, darker anteriorly, covered with sparse hairs. Fovea oval, hollowed. Chelicerae (Fig. 10G) yellow, with two promarginal teeth and one retromarginal tooth fissident with two cusps. Endites, labium, and sternum (Fig. 10E) yellow. Legs pale to red-yellow. Spination of leg I (Fig. 10H): femur v2-2-2-2; metatarsus v0-1-1. Abdomen (Fig. 10D-E) elongated, slightly contracted medially; dorsum brown, pale median-laterally and dark posteriorly, with two pairs of muscle depressions and herringbone stripes; venter pale brown to dark brown, with dots posteriorly. Palp (Fig. 9A-F): patella swollen; tibia wider than long; retrolateral tibial apophysis L-shaped and sclerotized, slightly broadened medially and curved apically; cymbium with dorsal and prolateral apophyses; bulb inflated, with sperm duct extending along margin; embolus coiled spirally, apically extending above the cymbium apex; median apophysis strongly sclerotized, consisting of square and trapeziform parts in retrolateral view.

Female (TRU-Salticid-0024)

Total length 4.48. Carapace 1.89 long, 1.41 wide. Abdomen 2.41 long, 1.23 wide. Eye sizes and interdistances: AME 0.44, ALE 0.25, PLE 0.22, AREW 1.38, PERW 1.47, EFL 1.07. Legs: I 4.96 (1.54, 2.66, 0.44, 0.32), II 3.22(1.02, 1.20, 0.68, 0.32), III 3.51 (1.05, 1.27, 0.85, 0.34), IV 4.81 (1.37, 1.90, 1.20, 0.34). Carapace (Fig. 10F) similar to that of male except paler. Abdomen (Fig. 10F) elongated, lacking contraction; dorsum brown, with four transverse white patches median-posteriorly, covered by white and brown hairs. Epigyne (Fig. 10A-C): almost as long as wide, with a pair of anterior arcuated rims and a bell-shaped anterior hood slightly wider than long; atrium large, separated by a narrow median septum; copulatory openings located antero-laterally; copulatory ducts curved anteriorly and then descending median-posteriorly, terminally with short gland ducts; spermathecae oval, touching each other; fertilization ducts extending transversely.

\section{Distribution}

China (Hubei, Guizhou) (Fig. 18).

Synagelides subgambosus sp. nov. urn:1sid:zoobank.org:act:A5482851-ABE8-47DB-AE07-352643E4DECA

Figs $11 \mathrm{~A}-\mathrm{C}, 12$

\section{Differential diagnosis}

Synagelides subgambosus sp. nov. closely resembles S. gambosus (Xie \& Yin 1990: figs 1-7; Fig. 11D) in the shape of the copulatory organs and habitus but differs in: 1) the terminal edge of median apophysis is smooth in retrolateral view in S. subgambosus sp. nov. (Fig. 11B), whereas it is distinctly serrated in S. gambosus (Fig. 11D); 2) the middle portion of median apophysis is about four-fifths the width of the 
terminal portion in retrolateral view in S. subgambosus sp. nov. (Fig. 11B), whereas it is about half the width of terminal portion in S. gambosus (Fig. 11D); 3) gland ducts are more than two-thirds as long as spermatheca in S. subgambosus sp. nov. (Fig. 12C), whereas less than one-fourth as long as spermatheca in S. gambosus (Xie \& Yin 1990: fig. 7). Synangelides subgambosus sp. nov. also somewhat resembles S. bohdanowiczi sp. nov. and the diagnostic features of this species are discussed above.

\section{Etymology}

The specific name refers to its similarity with $S$. gambosus, noun.

\section{Material examined}

\section{Holotype}

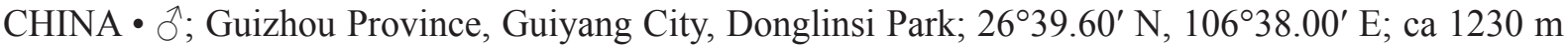
a.s.1.; 9-10 Apr. 2018; Cheng Wang leg.; TRU-Salticid-0028.

\section{Paratypes}

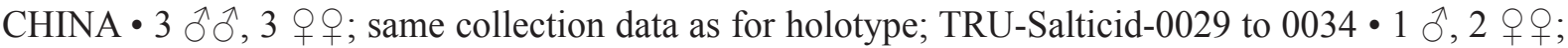
same collection data as for holotype; 26 Apr. 2018; Cheng Wang leg.; TRU-Salticid-0035 to 0037 •

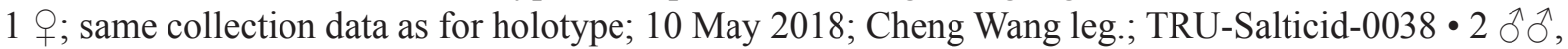
2 우; same collection data as for holotype; 16-18 May 2018; Cheng Wang leg.; TRU-Salticid-0039 to 0042 • 1 q; same collection data as for holotype; 23 May 2018; Cheng Wang leg.; TRU-Salticid-0043.

\section{Description}

Male (holotype)

Total length 3.47. Carapace 1.64 long, 1.17 wide. Abdomen 1.78 long, 0.92 wide. Eye sizes and interdistances: AME 0.36, ALE 0.19, PLE 0.18, AREW 1.13, PERW 1.16, EFL 0.95. Legs: I 4.19 (1.32, 2.17, $0.41,0.29)$, II $2.75(0.85,1.02,0.56,0.32)$, III 2.91 (0.88, 0.98, 0.71, 0.34), IV $3.87(1.12,1.41,0.95,0.39)$. Carapace (Fig. 12D) stippled, red-brown, darker anteriorly, covered with thin hairs antero-medially. Fovea oval, hollowed. Chelicerae (Fig. 12G) yellow, with two promarginal teeth and one retromarginal tooth fissident. Endites, labium and sternum (Fig. 12E) yellow. Legs pale yellow to red-yellow except femora I and IV red-brown. Spination of leg I (Fig. 12H): femur v2-2-2-2; metatarsus v0-2-2. Abdomen (Fig. 12D-E) elongated, dorsum with 2 pairs of muscle depressions and 2 transverse pale patches medially; venter gray-white, with a pair of pale brown lines extending from epigastric furrow to the terminus. Palp (Fig. 11A-C): patella swollen; tibia almost as long as wide; retrolateral tibial apophysis S-shaped, originating from the middle part of tibia; cymbium with a well-developed retrolateral apophysis; embolus enlarged at base, strongly curved medially and blunt at tip; median apophysis flattened, slightly broadened terminally, and with a triangular process at the anterior edge in retrolateral view.

Female (allotype, TRU-Salticid-0032)

Total length 4.22. Carapace 1.73 long, 1.18 wide. Abdomen 2.43 long, 1.55 wide. Eye sizes and interdistances: AME 0.38, ALE 0.24, PLE 0.22, AREW 1.18, PERW 1.20, EFL 0.96. Legs: I $3.81(1.20,1.88$, $0.44,0.29)$, II $2.74(0.85,1.01,0.56,0.32)$, III $2.94(0.85,1.01,0.76,0.32)$, IV $4.08(1.15,1.51,1.05$, 0.37). Habitus (Fig. 12F) similar to that of male except paler. Epigyne (Fig. 12A-C) slightly wider than long, with a pair of lateral arcuated rims; atrium large, almost covering two-thirds the epigyne, separated by a narrow median septum; copulatory openings located postero-laterally; copulatory ducts extending transversely at antero-median part and then descending posteriorly along the longitudinal axis, terminally with well-developed gland ducts which are longer than the fertilization ducts; spermathecae elongated, extending transversely and touching each other prolaterally; fertilization ducts short.

\section{Distribution}

China (Guizhou) (Fig. 18). 


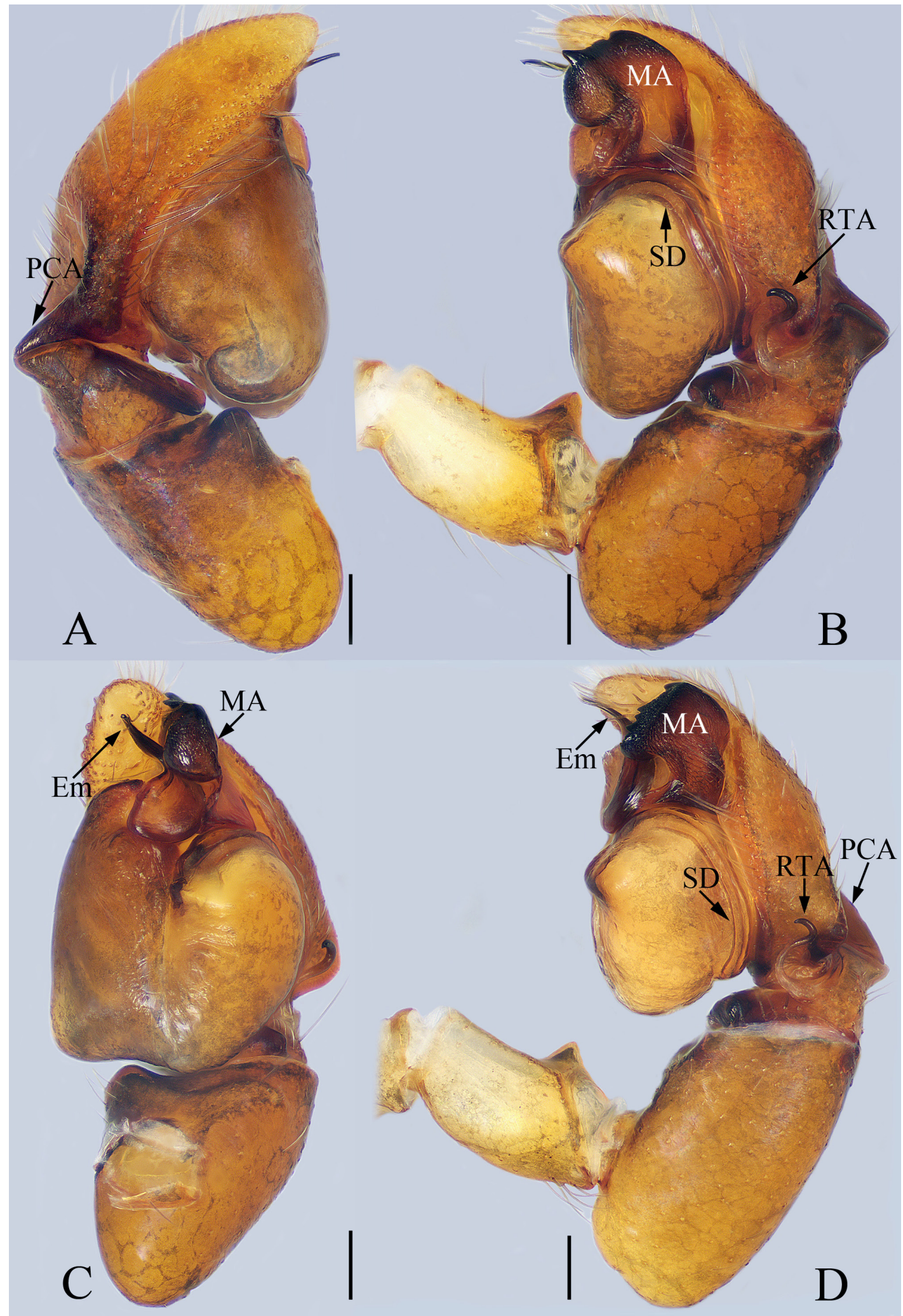

Fig. 11. Male palp of Synagelides subgambosus sp. nov. and S. gambosus Xie \& Yin, 1990. A-C. S. subgambosus, holotype, §ิ (TRU-Salticid-0028). D. S. gambosus, ô (TRU-Salticid-0052). A. Prolateral view. B, D. Retrolateral view. C. Ventral view. Abbreviations: see Material and methods. Scale bars $=0.1 \mathrm{~mm}$. 

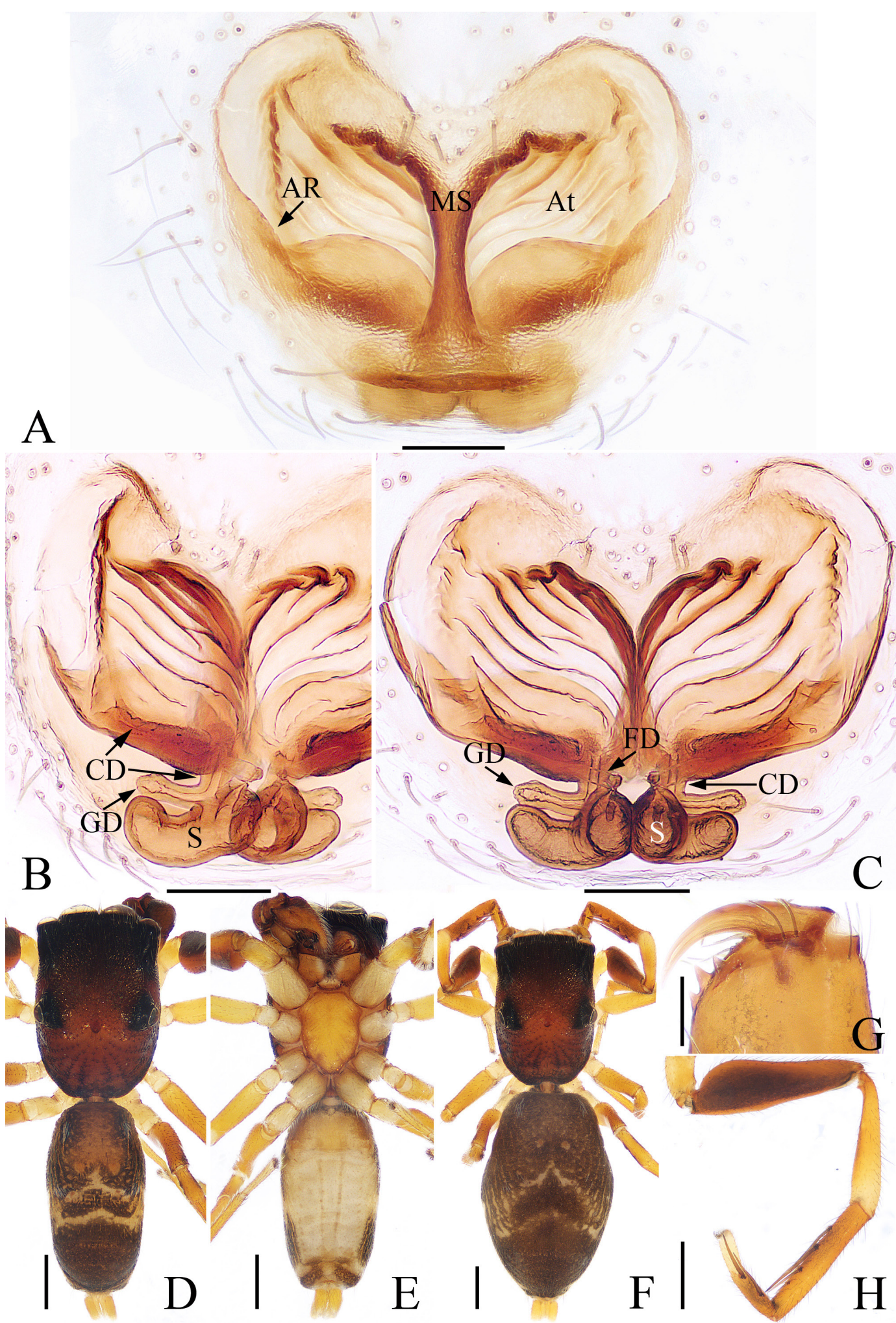

Fig. 12. Synagelides subgambosus sp. nov. A-C, F. Paratype, $q$ (TRU-Salticid-0032). D-E, G-H. Holotype, $\widehat{\partial}$ (TRU-Salticid-0028). A. Epigyne, ventral view. B. Epigyne, dorsolateral view. C. Epigyne, dorsal view. D. Habitus, dorsal view. E. Habitus, ventral view. F. Habitus, dorsal view. G. Chelicerae, dorsal view. H. Leg I, prolateral view. Abbreviations: see Material and methods. Scale bars: $\mathrm{A}-\mathrm{C}, \mathrm{G}=0.1 \mathrm{~mm}$; D-F, $\mathrm{H}=0.5 \mathrm{~mm}$. 


\section{Synagelides wuliangensis sp. nov. urn:1sid:zoobank.org:act:C9E27211-4188-4EAD-A876-344DA8CEE9A6}

Figs 13-14

\section{Differential diagnosis}

Synagelides wuliangensis sp. nov. resembles S. hamatus Zhu, Zhang, Zhang \& Chen, 2005 (Zhu et al. 2005: fig. 12a-e) in the shape of the copulatory organs and habitus, but differs in: 1) the second retrolateral tibial apophysis is about two times longer than wide in $S$. wuliangensis sp. nov. (Fig. 13B), whereas slightly wider than long in S. hamatus (Zhu et al. 2005: fig. 12e); 2) retrolateral tibial apophysis tapers to a tail-shaped terminus in S. wuliangensis sp. nov. (Fig. 13B), whereas it becomes short, spine-shaped and terminates abruptly in S. hamatus (Zhu et al. 2005: fig. 12e); 3) epigynal hood is more than three times longer than wide in S. wuliangensis sp. nov. (Fig. 14A), whereas almost as long as wide in S. hamatus (Zhu et al. 2005: fig. 12b); 4) spermathecae are oval in S. wuliangensis sp. nov. (Fig. 14C), whereas reniform in S. hamatus (Zhu et al. 2005: fig. 12c). Synagelides wuliangensis sp. nov. also somewhat resembles $S$. logunovi sp. nov. in the general shape of copulatory organs, but can be distinguished by the absence of the retrolateral patellar apophysis and the epigynal hood being more than three times longer than wide in S. wuliangensis sp. nov. (Fig. 174A), whereas the patella retrolateral apophysis is present and the epigynal hood is slightly longer than wide in $S$. logunovi (Fig. 8A).

\section{Etymology}

The species name comes from the type locality; adjective.

\section{Material examined}

\section{Holotype}

CHINA - $\hat{O}^{\text {; }}$ Y Yunnan Province, Nanjian County, Lingbaoshan National Forest Park of Wuliangshan National Nature Reserve; 2446.02' N, 100³1.19' E; ca 2290 m a.s.l.; 13 Aug. 2015; Cheng Wang, Zhaolin Liao, Peng Luo and Gaotao Liu leg.; TRU-Salticid-0044.

\section{Paratypes}

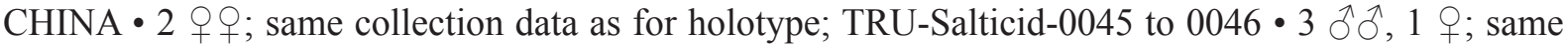
collection data as for holotype; 12 Aug. 2015; TRU-Salticid-0047 to 0050 • 1 j; Gonglang Village; $24^{\circ} 15.79^{\prime} \mathrm{N}, 100^{\circ} 44.43^{\prime}$ E; ca 2010 m a.s.1.; 2 Aug. 2015, Xiaoqi Mi, Mingyong Liao, Tianjun Liu and Xing Kuang leg.; TRU-Salticid-0051.

\section{Description}

Male (holotype)

Total length 3.71. Carapace 1.58 long, 1.32 wide. Abdomen 2.18 long, 1.01 wide. Eye sizes and interdistances: AME 0.37, ALE 0.19, PLE 0.18, AREW 1.13, PERW 1.30, EFL 0.96. Legs: I 6.00 (1.90, $2.98,0.66,0.46)$, II $3.05(0.95,1.15,0.63,0.32)$, III $3.15(0.95,1.10,0.76,0.34)$, IV $4.16(1.15,1.63$, 1.01, 0.37). Carapace (Fig. 14D) stippled, red-brown, dark anteriorly, covered with brown hairs laterally and anteriorly. Eye base black except AME base brown. Fovea oval, hollowed. Chelicerae (Fig. 14G) yellow, with two promarginal teeth and one retromarginal tooth fissident. Endites, labium, and sternum (Fig. 14E) pale yellow. Legs pale yellow to red-yellow. Spination of leg I (Fig. 14H): femur v2-2-2-2-2; metatarsus v0-2-2. Abdomen (Fig. 14D-E) elongated; dorsum brown anteriorly and dark posteriorly, with two pairs of muscle depressions and several herringbone stripes; venter gray-white, with dotted lines medially. Palp (Fig. 13A-F): patella swollen; retrolateral tibial apophysis slender, longer than half the cymbial length, pointed apically; the second retrolateral tibial apophysis paliform, about two times as long as wide; cymbium hairy, with dorsal and prolateral apophyses; bulb inflated; embolus tapered, coiled spirally; median apophysis complicated and sclerotized. 


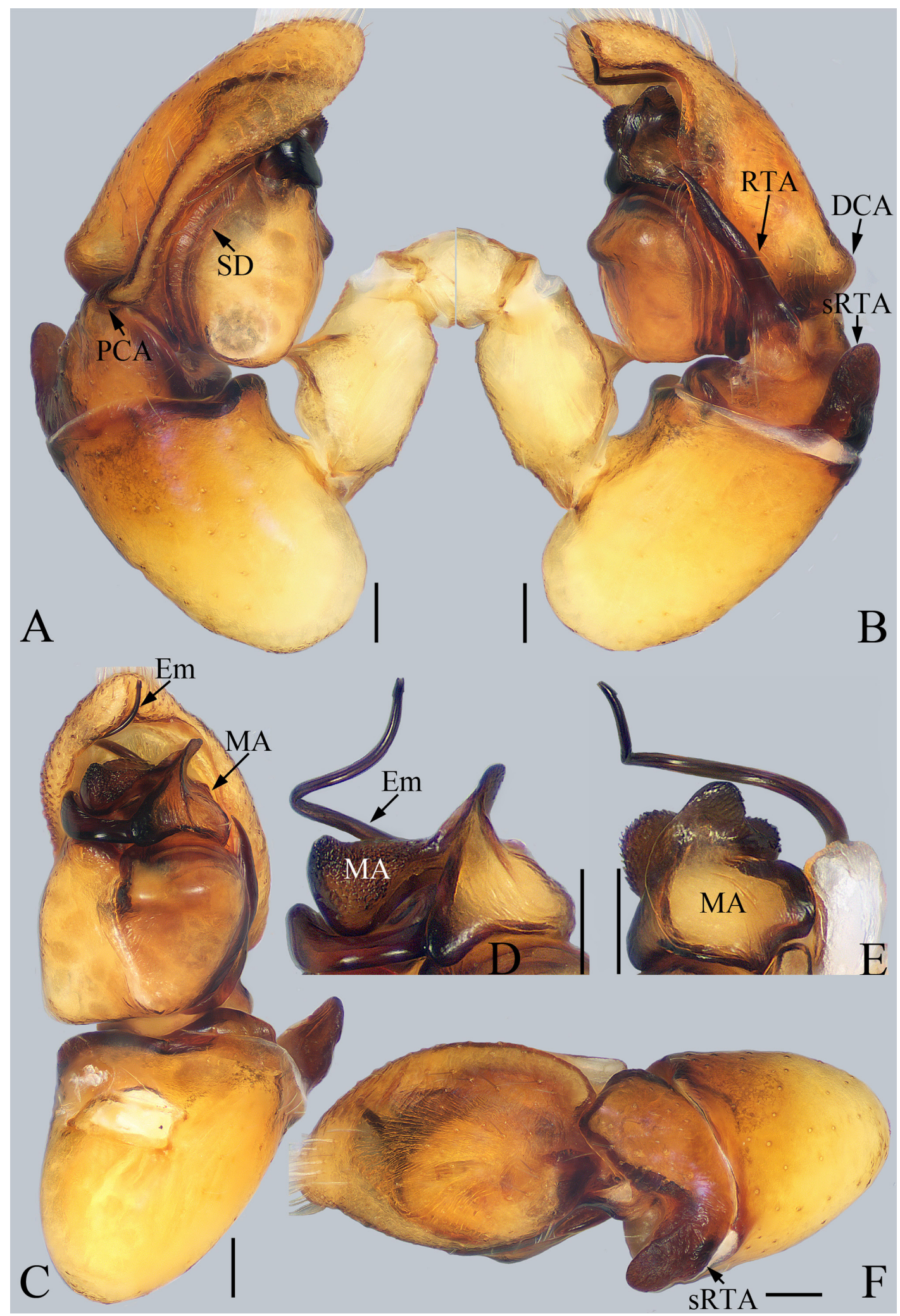

Fig. 13. Male palp of Synagelides wuliangensis sp. nov. A-C, F. Holotype, ô (TRU-Salticid-0044). D-E. Paratype, ô (TRU-Salticid-0047). A. Prolateral view. B. Retrolateral view. C. Ventral view. D. Embolus and median apophysis, ventral view. E. Embolus and median apophysis, retrolateral view. F. Dorsal view. Abbreviations: see Material and methods. Scale bars $=0.1 \mathrm{~mm}$. 


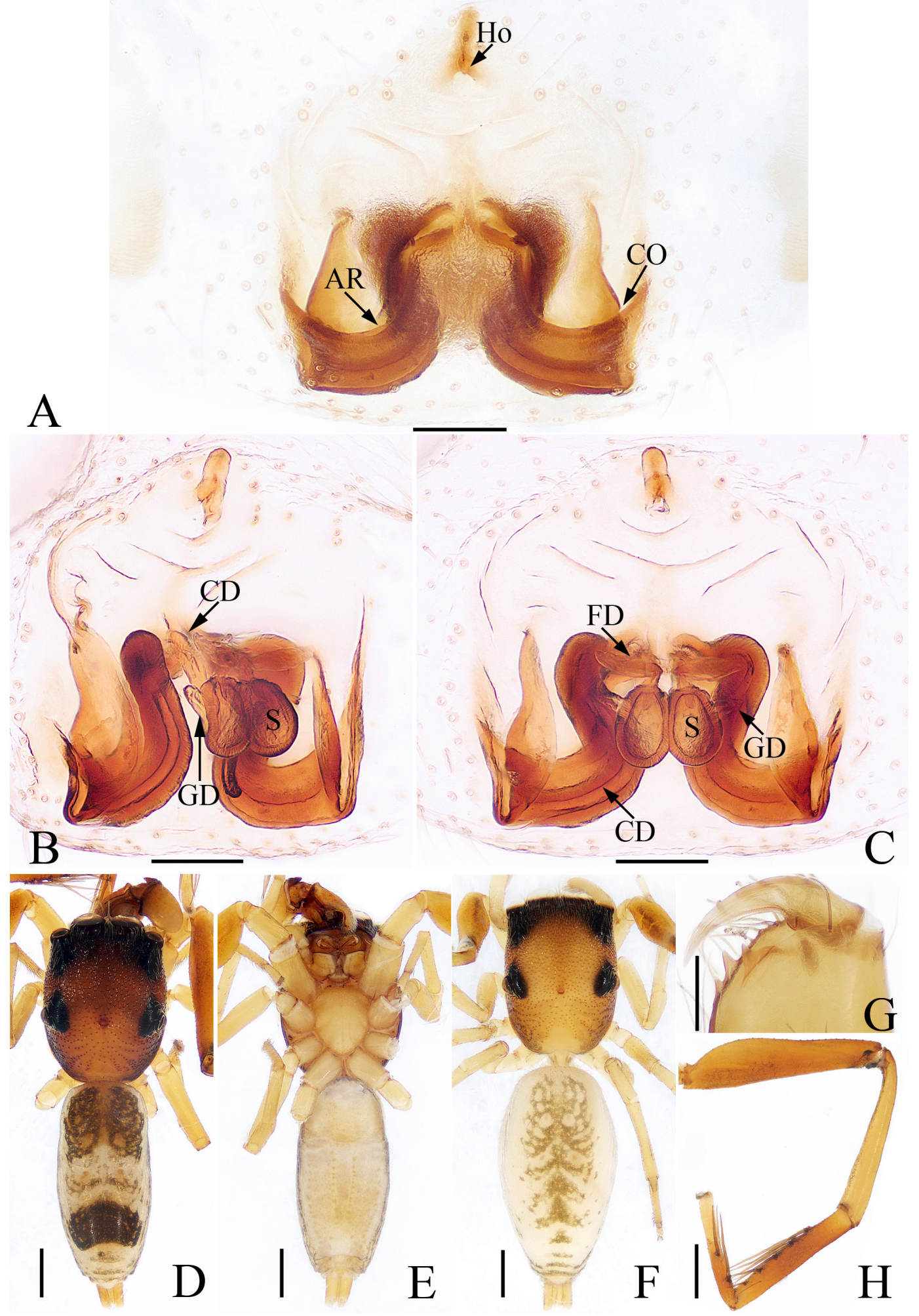

Fig. 14. Synagelides wuliangensis sp. nov. A-C, F. Paratype, $q$ (TRU-Salticid-0050). D-E, G-H. Holotype, $\widehat{\jmath}$ (TRU-Salticid-0044). A. Epigyne, ventral view. B. Epigyne, dorsolateral view. C. Epigyne, dorsal view. D. Habitus, dorsal view. E. Habitus, ventral view. F. Habitus, dorsal view. G. Chelicerae, dorsal view. H. Leg I, prolateral view. Abbreviations: see Material and methods. Scale bars: $\mathrm{A}-\mathrm{C}, \mathrm{G}=0.1 \mathrm{~mm}$; D-F, $\mathrm{H}=0.5 \mathrm{~mm}$. 
Female (allotype, TRU-Salticid-0050)

Total length 4.11. Carapace 1.62 long, 1.22 wide. Abdomen 2.35 long, 1.30 wide. Eye sizes and interdistances: AME 0.37, ALE 0.20, PLE 0.19, AREW 1.14, PERW 1.26, EFL 0.93. Legs: I 4.13 (1.21, 2.07, 0.51, 0.34), II 2.72 (0.85, 1.01, 0.54, 0.32), III 2.93 (0.90, 1.01, 0.68, 0.34), IV 3.96 (1.07, 1.51, 1.01, 0.37). Habitus (Fig. 14F) similar to those of males except paler. Epigyne (Fig. 14A-C) longer than wide, with an anterior hood more than three times longer than wide and a pair of posterior arcuated rims; copulatory openings located postero-laterally; copulatory ducts ascending in a S-shape before descending, terminally with short gland ducts which are almost half as long as fertilization ducts; spermathecae oval, touching each other; fertilization ducts extending transversely.

\section{Distribution}

China (Yunnan) (Fig. 18).

Synagelides xingdouensis sp. nov. urn:lsid:zoobank.org:act:5BC3FCBD-DFF5-453A-B5BB-8BB56566776D

Figs $15-16$

\section{Differential diagnosis}

Synagelides xingdouensis sp. nov. can be easily distinguished from all other congeners by: male palp has three tibial apophyses in S. xingdouensis sp. nov. whereas none, one or two tibial apophyses in other congeners; spermathecae are mainly anterior to copulatory ducts and about three-fourth as long as epigynum in $S$. xingdouensis sp. nov., whereas mainly posterior to copulatory ducts and shorter than half the epigynal length in all other congeners.

\section{Etymology}

The species name comes from the type locality; adjective.

\section{Material examined}

Holotype

CHINA - ô; Hubei Province, Enshi Tujia and Miao Autonomous Prefecture, Xianfeng County, Huangjindong Town, Maliuxi Village, Xingdoushan National Nature Reserve; $29^{\circ} 57.00^{\prime} \mathrm{N}, 109^{\circ} 1.54^{\prime} \mathrm{E}$, ca 860 m a.s.l.; 22 Aug. 2017; Guchun Zhou, Tian Tian and Zongguang Huang leg.; HNU-20170513-1.

\section{Paratypes}

CHINA • 2 우; same collection data as for holotype; HNU-20170513-2 to 20170513-3.

\section{Description}

Male (holotype)

Total length 3.32. Carapace 1.54 long, 1.14 wide. Abdomen 1.71 long, 0.95 wide. Eye sizes and interdistances: AME 0.39, ALE 0.20, PLE 0.19, AREW 1.13, PERW 1.15, EFL 0.94. Legs: I $3.91(1.22,1.93$, $0.44,0.32)$, II $2.59(0.78,0.93,0.54,0.34)$, III 2.76 (0.83, 0.88, 0.71, 0.34), IV 3.70 (1.02, 1.39, 0.90, 0.39). Carapace (Fig. 16D) stippled, brown, with a pair of indistinct dark patches anteriorly, bearing hairs at the anterior margin and bilateral sides. Eye base black except AME base brown. Fovea oval, hollowed. Chelicerae (Fig. 16G) yellow, with two promarginal teeth and one retromarginal tooth fissident with two cusps. Endites, labium, and sternum pale yellow (Fig. 16E). Legs pale yellow to green-yellow. Spination of leg I (Fig. 16H): femur v2-2-2-2-2; metatarsus v0-2-2. Abdomen (Fig. 16D-E) oval; dorsum brown, with two pairs of muscle depressions and a transverse white band followed by an indistinct transverse yellow patch; venter gray-white. Palp (Fig. 15A-D): patella about 1.5 times longer than wide; 


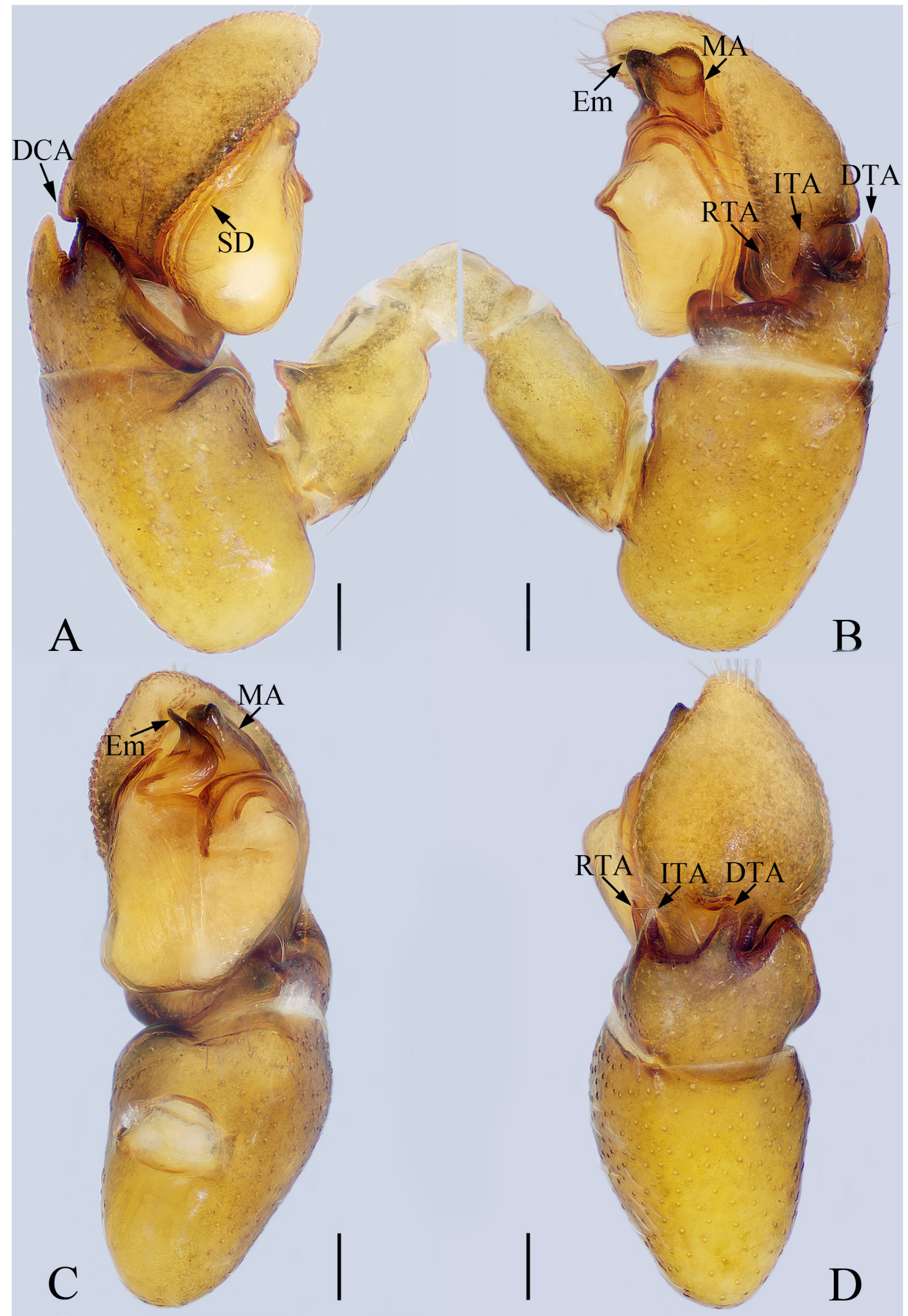

Fig. 15. Male palp of Synagelides xingdouensis sp. nov., holotype, đ̊ (HNU-20170513-1). A. Prolateral view. B. Retrolateral view. C. Ventral view. D. Dorsal view. Abbreviations: see Material and methods. Scale bars $=0.1 \mathrm{~mm}$. 

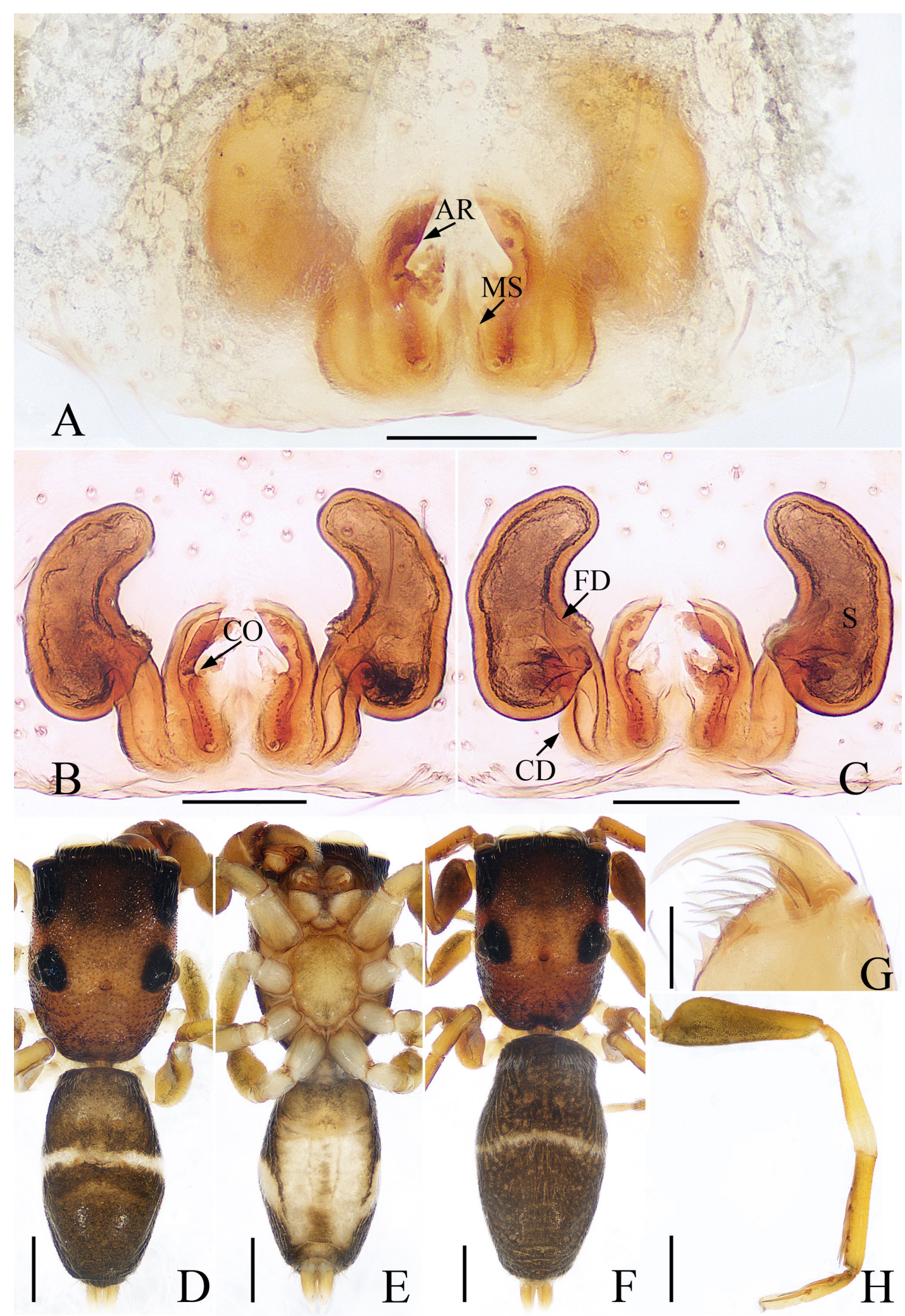

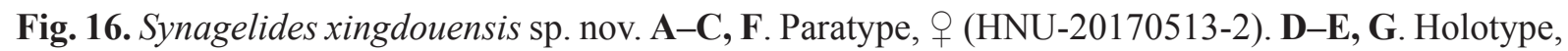

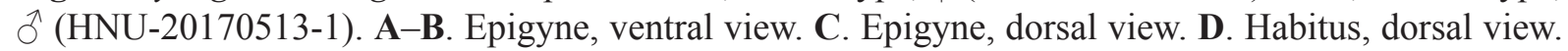
E. Habitus, ventral view. F. Habitus, dorsal view. G. Chelicerae, dorsal view. H. Leg I, prolateral view. Abbreviations: see Material and methods. Scale bars: A-C, G $=0.1 \mathrm{~mm}$; D-F, H $=0.5 \mathrm{~mm}$. 

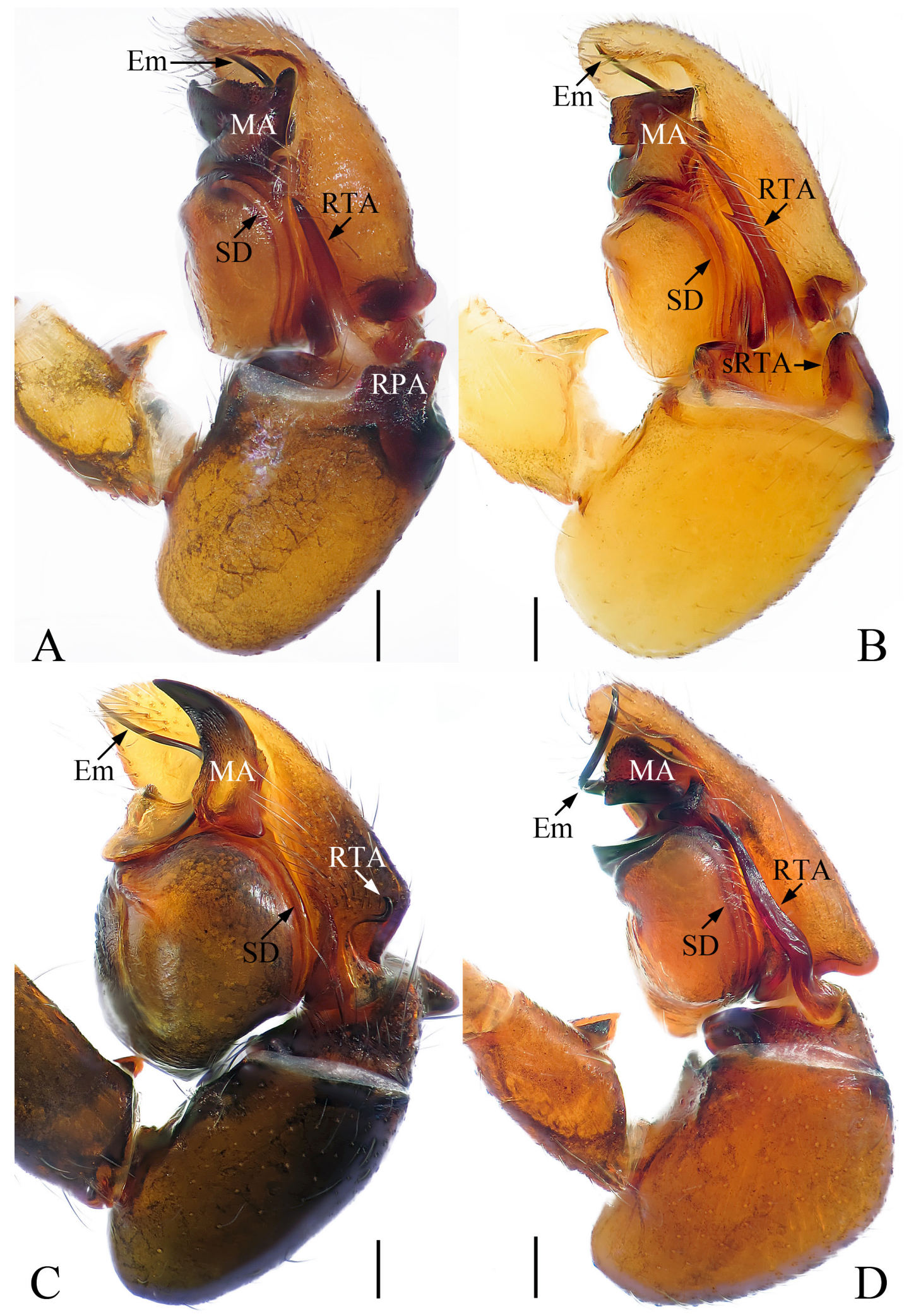

Fig. 17. Male palp of Synagelides spp. A, C. Holotype, retrolateral view. B, D. Male, retrolateral view. A. S. logunovi sp. nov. (TRU-Salticid-0016). B. S. forkiforma Yang, Zhu \& Song, 2007 (HNU-2004042801). C. S. bohdanowiczi sp. nov. (TRU-Salticid-0010). D. S. palpalis Żabka, 1985 (TRU-Salticid-0053). Abbreviations: see Material and methods. Scale bars $=0.1 \mathrm{~mm}$. 
retrolateral tibial apophysis tapering to a slightly pointed tip; intermediate tibial apophysis triangular, transparent apically; dorsal tibial apophysis tapering, digitiform in dorsal view; embolus short, broad and flattened antero-medially and abruptly narrowed posteriorly; median apophysis bifurcated terminally in retrolateral view.

Female (allotype, HNU-20170513-2)

Total length 3.87. Carapace 1.63 long, 1.18 wide. Abdomen 2.21 long, 1.16 wide. Eye sizes and interdistances: AME 0.40, ALE 0.22, PLE 0.20, AREW 1.20, PERW 1.22, EFL 0.96. Legs: I 3.74 (1.10, 1.88, $0.44,0.32)$, II $2.69(0.85,0.98,0.54,0.32)$, III 2.96 (0.85, 1.01, 0.71, 0.39) IV $3.99(1.10,1.49,1.01$, 0.39). Habitus (Fig. 16F) similar to that of male except darker. Epigyne (Fig. 16A-C) wider than long, with a pair of middle arcuated rims; atrium small, separated by a nib-shaped median septum; copulatory openings beneath the base of epigynal rims; copulatory ducts almost U-shaped; spermathecae large, reniform, extending longitudinally, about three-fourth as long as epigynum and separated from each other by 1.5 times their width; fertilization ducts extending obliquely.

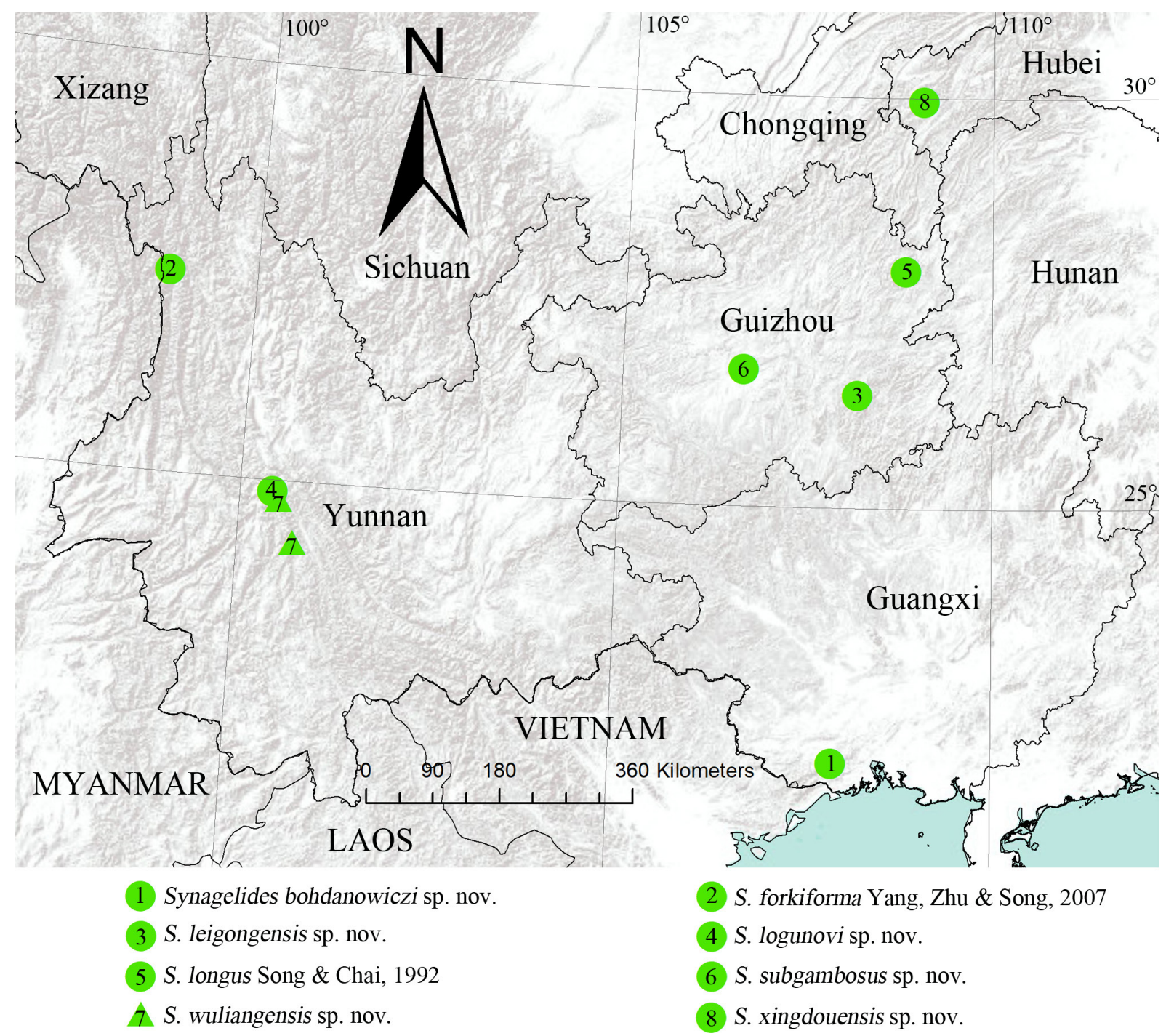

Fig. 18. Distributional map of eight species of Synagelides Strand, 1906: S. bohdanowiczi sp. nov.; S. forkiforma Yang, Zhu \& Song, 2007; S. leigongensis sp. nov.; S. longus Song \& Chai, 1992; S. logunovi sp. nov., S. subgambosus sp. nov.; S. wuliangensis sp. nov.; S. xingdouensis sp. nov. 


\section{Distribution}

China (Hubei) (Fig. 18).

\section{Discussion}

Within the genus Synagelides, five groups were established by Bohdanowicz (1987): S. agriformis-group, $S$. annae-group, $S$. nishikawai-group, $S$. cavaleriei-group, and S. palpalis-group. Since then, surprisingly, no other species have been assigned to these groups. Based on morphology, many species, including some of the six new species described here, can be placed into one of these five groups. For example, S. longus and S. palpaloides can be placed into the S. palpalis-group given that the habitus and copulatory organs of these two species are similar to $S$. palpalis. Other species can be placed together in new groups. S. subgambosus sp. nov. and S. gambosus can be placed together into a new group given that for both species, the male palp has a S-shaped retroalteral tibial apophysis and the female epigyne has a long and narrow median septum and a pair of lateral arcuated rims. Nevertheless, several species (e.g., S. xingdouensis sp. nov., S. leigongensis sp. nov. and $S$. yunnan Song \& Zhu, 1998) are so unique that they cannot be placed into a group with any other species. Moreover, it is challenging to group species exclusively based on morphological characters from a limited number of specimens (Zhang et al. 2019). Based on that, no species are formally assigned to existing groups or placed in new groups in the present contribution.

Like most salticid genera, one major problem with the taxonomy of Synagelides is that the known diversity may be overestimated given that many species are known only from a single sex and further investigations may show that some species known only from males may prove to be synonymous with other species known only from females and vice versa. However, most species of Synagelides have very localized distributions and mainly occur in mountains above 1000 meters, indicating more species could be discovered from remote areas and isolated mountains. Therefore, there is no doubt that the true diversity of the genus remains poorly studied.

\section{Acknowledgments}

The manuscript benefited greatly from comments by Rudy C.A.M. Jocqué and two anonymous referees. We are grateful to Prof. Zi-Zhong Yang for providing the clear illustrations of the holotype of Synagelides forkiforma Yang, Zhu \& Song, 2007, to Prof. Charles Griswold, Prof. D.H. Kavanaugh, Dr Gu-Chun Zhou, Zong-Guang Huang, Tian Tian, Zhao-Lin Liao, Peng Luo, Gao-Tao Liu, Tian-Jun Liu, Xing Kuang, Feng-E. Li, Ting-rong Peng, Gui-Jie Tian and Hong Liu for collecting the specimens. We are grateful to Stephanie F. Loria (American Museum of Natural History, New York, USA) for reviewing the English of this manuscript. This research was supported by the National Special Fund on Basic Research of Science and Technology of China (No. 2014FY110100). It is also partly sponsored by the Hunan Provincial Program for Development of Key Disciplines in Ecology (grant number No. 0713), the National Natural Sciences Foundation of China (NSFC-30970327, 31272271, 31272272, 31301861, 31660609), Science and Technology Cooperation Project Foundation of Guizhou Province [grant number LH-2016/7303, LH-2017/7326], Natural Science Research Project Foundation of Guizhou Province of education [grant number KY[2018]345], Hunan Provincial Natural Science Foundation of China (No. 11JJ1004/ 12JJ3028), the Program for New Century Excellent Talents in University (NCET12-0717), China Postdoctoral Science Foundation (No. 20100471221/201104506), and the program of Hunan Provincial Science and Technology Plans (No. 2010RS4006).

\section{References}

Bohdanowicz A. 1978. Ergebnisse der Bhutan-Expedition 1972 des Naturhistorischen Museums in Basel. Araneae: Fam. Salticidae Genus Synagelides. Entomologica Basiliensis 3: 23-30. 
Bohdanowicz A. 1979. Descriptions of spiders of the genus Synagelides (Araneae: Salticidae) from Japan and Nepal. Acta Arachnologica 28: 53-62.

Bohdanowicz A. 1987. Salticidae from the Nepal Himalayas: The genus Synagelides Bösenberg \& Strand 1906. Courier Forschungsinstitut Senckenberg 93: 65-86.

Bösenberg W. \& Strand E. 1906. Japanische Spinnen. Abhandlungen der Senckenbergischen Naturforschenden Gesellschaft 30: 93-422.

Kanesharatnam N. \& Benjamin S.P. 2020. First record of Synagelides Strand, 1906 (Araneae: Salticidae) from Sri Lanka: description of four endemic species from tropical wet forest of the island. Zootaxa 4790 (1): 43-56. https://doi.org/10.11646/zootaxa.4790.1.2

Lin Y.J. \& Li S.Q. 2020. Two new genera and eight new species of jumping spiders (Araneae, Salticidae) from Xishuangbanna, Yunnan, China. ZooKeys 952: 95- 128.

https://doi.org/10.3897/zookeys.952.51849

Liu K., Chen Z.W., Xiao Y., Xu X. \& Peng X.J. 2017. Three new species of Synagelides Strand, 1906 from China (Araneae: Salticidae). Zootaxa 4350 (2): 291-300. https://doi.org/10.11646/zootaxa.4350.2.5

Logunov D.V. \& Hereward J. 2006. New species and synonymies in the genus Synagelides Strand in Bösenberg \& Strand, 1906 (Araneae: Salticidae). Bulletin of the British Arachnological Society 13: 281-292.

Maddison W.P. 2015. A phylogenetic classification of jumping spiders (Araneae: Salticidae). Journal of Arachnology 43 (3): 231-292. https://doi.org/10.1636/arac-43-03-231-292

Peng X.J. 2020. Fauna Sinica, Invertebrata 53, Arachnida: Araneae: Salticidae. Science Press, Beijing.

Peng X.J., Yin C.M., Yan H.M. \& Kim J.P. 1998. Five jumping spiders of the family Salticidae (Arachnida: Araneae) from China. Korean Arachnology 14 (2): 36-43.

Peng X.J., Tso I.M. \& Li S.Q. 2002. Five new and four newly recorded species of jumping spiders from Taiwan (Araneae: Salticidae). Zoological Studies 41: 1-12.

Peng X.J., Li S.Q. \& Chen J. 2003. Description of Synagelides zhaoi sp. nov. from Hubei, China (Araneae, Salticidae). Acta Zootaxonomica Sinica 28: 249-251.

Peng X.J., Tang G. \& Li S.Q. 2008. Eight new species of salticids from China (Araneae, Salticidae). Acta Zootaxonomica Sinica 33: 248-259.

Schenkel E. 1963. Ostasiatische Spinnen aus dem Muséum d'Histoire naturelle de Paris. Mémoires du Muséum national d'histoire naturelle, Série A, Zoologie 25: 1-481.

Song D.X. 1990. On four new species of soil spiders (Arachnida: Araneae) from China. Journal of Hubei University, Natural Science Edition 12: 340-345.

Song D.X. \& Chai J.Y. 1992. On new species of jumping spiders (Araneae: Salticidae) from Wuling Mountains area, southwestern China. Journal of Xinjiang University 9(3): 76-86.

Song D.X. \& Li S.Q. 1997. Spiders of Wuling Mountains area. In: Song, D. X. (ed.) Invertebrates of Wuling Mountains Area, Southwestern China: 400-448. Science Press, Beijing.

Song D.X. \& Zhu M.S. 1998. Two new species of the family Salticidae (Araneae) from China. Acta Arachnologica Sinica 7: 26-29.

Song D.X., Zhu M.S. \& Chen J. 1999. The Spiders of China. Hebei Science and Technology Publishing House, Shijiazhuang.

World spider catalog. 2020. World Spider Catalog, ver. 20.5. Natural History Museum Bern. Available from http://wsc.nmbe.ch [accessed 18 Aug. 2020]. https://doi.org/10.24436/2 
Xie L.P. \& Yin C.M. 1990. Two new species and three newly recorded species of the genus Synagelides from China (Araneae: Salticidae). Acta Zootaxonomica Sinica 15: 298-304.

Yang Z.Z., Zhu M.S. \& Song D.X. 2007. Report of two new species of the genus Synagelides Strand, 1906 from China (Araneae: Salticidae). Journal of Dali University 6 (2): 1-4.

Żabka M. 1985. Systematic and zoogeographic study on the family Salticidae (Araneae) from VietNam. Annales Zoologici, Warszawa 39: 197-485.

Zhang H., Jäger P. \& Liu J. 2019. Establishing a new species group of Pseudopoda Jäger, 2000 with the description of two new species (Araneae, Sparassidae). ZooKeys 879: 91-115.

https://doi.org/10.3897/zookeys.879.35110

Zhu M.S., Zhang J.X., Zhang Z.S. \& Chen H.M. 2005. Arachnida: Araneae. In: Yang M.F. \& Jin D.C. (eds) Insects from Dashahe Nature Reserve of Guizhou: 490-555. Guizhou People's Publishing House, Guiyang.

Manuscript received: 29 August 2019

Manuscript accepted: 27 July 2020

Published on: 18 November 2020

Topic editor: Rudy Jocqué

Desk editor: Pepe Fernández

Printed versions of all papers are also deposited in the libraries of the institutes that are members of the EJT consortium: Muséum national d'histoire naturelle, Paris, France; Meise Botanic Garden, Belgium; Royal Museum for Central Africa, Tervuren, Belgium; Royal Belgian Institute of Natural Sciences, Brussels, Belgium; Natural History Museum of Denmark, Copenhagen, Denmark; Naturalis Biodiversity Center, Leiden, the Netherlands; Museo Nacional de Ciencias Naturales-CSIC, Madrid, Spain; Real Jardín Botánico de Madrid CSIC, Spain; Zoological Research Museum Alexander Koenig, Bonn, Germany; National Museum, Prague, Czech Republic. 